U.S. Department of Commerce

National Bureau of Standards
NBSIR

80-2179-R

\title{
Type Approval Criteria and Test Procedures
}

\section{Prepared for the Talsk Forree of}

Netional Type Approval of the National Conference on

\section{Weights and Measures}

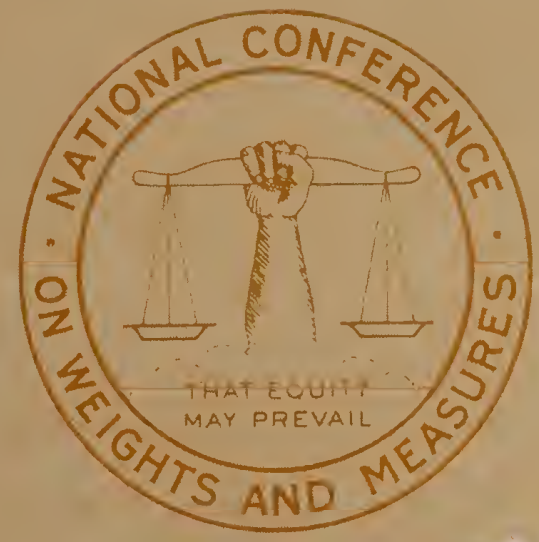



NBSIR 80-2179

\section{TYPE APPROVAL}

\section{CRITERIA AND}

TEST PROCEDURES

Prepared for the Task Force on National Type Approval of the

National Conference on

Weights and Measures

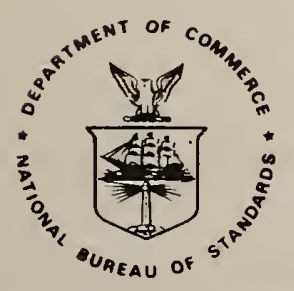

U.S. DEPARTMENT OF COMMERCE, Philip M. Klutznick, Secretary Jordan J. Baruch, Assistant Secretary for Productivity, Technology, and Innovation NATIONAL BUREAU OF STANDARDS. Ernest Ambler, Director 



\section{FOREWORD}

This document is a preliminary draft of a handbook on type approval criteria and procedures for weighing and measuring devices. The distribution of the draft is to solicit comments on whether the information is useful to manufacturers and weights and measures officials. The responses will determine if further development of written type approval criteria in the measurement areas covered in the draft and in other measurement areas should be pursued.

The development of checklists and test procedures is an effort to make both the manufacturer and the enforcement official aware of criteria currently being used in type approval examinations. It is also an attempt to standardize the criteria and test methods. The distribution of this draft document will provide a basis for discussion of possible directions for a national type approval program in the future. The checklists and test methods are intended to be sufficiently flexible to be easily changed to keep pace with technology and to permit innovation in the design of weighing and measuring equipment. 

November 12,1980

MEMORANDUM FOR Task Force on National Type Approval

Specifications and Tolerances Committee

Directors of Weights and Measures

Industry Representatives

From: Henry V. Oppermann fenzy
General Physical Scientist
Office of Weights and Measures

Subject: Draft Type Approval Criteria and Test Procedures

Uniform criteria and test procedures are necessary for a national type approval program. Drafts of checklists of type approval criteria and test procedures have been developed to aid in achieving reciprocity between jurisdictions. The drafts have also been prepared to inform manufacturers of the criteria and tests to be applied to devices submitted for type approval.

The drafts of the checklist for digital weighing equipment (item II), the performance tests (items VI through X), and the use of error weights with digital scales have been discussed by California, Federal Grain Inspection Service (FGIS), and Office of Weights and Measures (OWM) representatives and serve as the basis for reciprocity between organizations. The remaining drafts are in an early stage of development and are still being revised to establish a foundation for reciprocity between the organizations.

Eventually these drafts are intended to become the basis of a national type approval program. The drafts are being circulated for review and comment to obtain input from industry and enforcement representatives. Enforcement officials, especially those conducting their own type approval program, should review the drafts to determine if devices meeting the checklist criteria and passing the tests would satisfy their type approval requirements. They should also decide if they would accept the examination of a jurisdiction that has been trained in conducting a type approval examination using the checklists and test procedures, thereby eliminating duplicate type approval examinations. If a jurisdiction has any additional requirements, they should be sent to the Task Force on National Type Approval for possible incorporation into the checklists or procedures. Manufacturers should comment specifically whether or not the criteria are reasonable and the test procedures practical.

A11 items in the drafts are considered subject to change based upon the comments that are received. Comments on the operation of the current reciprocity program and recommendations for future development are encouraged. 
The plan for future development of the type approval program, criteria, and procedures is as follows. The criteria and procedures along with comments received will be submitted to the Task Force on National Type Approval for evaluation. The Task Force will recommend changes in criteria and procedures and provide guidance for future program development. The Specifications and Tolerances Committee (S\&T) will serve as the overseeing body to assure that the criteria and procedures are consistent with the requirements of NBS Handbook 44 and the intent of the Conference. Criteria and procedures that are challenged and cannot be resolved through the Task Force will be taken to the S\&T Committee for resolution. Any issues that cannot be resolved through the S\&T Committee will be submitted to the National Conference on Weights and Measures (NCWM) for a vote and possible inclusion in Handbook 44.

The checklists are much more specific than Handbook 44 . They are the result of decisions made in type approval examinations or reflect problems that have been experienced in examinations. The digital weighing equipment checklist reflects criteria that are currently being used in type approval examinations.

The checklists are to serve as a guide in product design so that a manufacturer can be aware of decisions that already have been made in previous examinations. The checklists are intended to be more flexible than Handbook 44. The checklists are not intended to stifle manufacturer innovations. If a manufacturer develops a new capability or new approach to a method of operation or develops a new argument on a previously decided issue and can convince the S\&T Committee of its merit, the checklist will be changed. An issue that is strongly contested by industry or enforcement officials can be taken before the NCWM for resolution. The checklists are intended to make the manufacturer aware, before production has been initiated, of criteria that will be applied to a device. Ideally, any conflicts with the criteria can be resolved in the design stage before considerable expense must be incurred to modify a unit.

THE CHECKLISTS ARE NOT TO BE USED BY WEIGHTS AND MEASURES OFFICIALS TO CHECK DEVICES CURRENTLY INSTALLED IN COMMERCIAL APPLICATIONS. The checklists are continually updated as new criteria are developed in type approval examinations. Devices currently in use may not have been tested against some of the criteria given in the checklists so it is not appropriate to apply the criteria retroactively. It is appropriate for the checklists to be used in an examination of new equipment that is being submitted to the State for type approval for the first time.

Apparently some misunderstandings exist about how companies can obtain Reports of Test or Certificates of Approval from California, FGIS, and NBS under the reciprocity program and the devices for which a reciprocity agreement exists. Reciprocity has been achieved between California and NBS on the most common digital weighing equipment. Digital weighing equipment for which reciprocity has not yet been achieved are hopper automatic batching systems, livestock, belt-conveyor, and railroad scales. Any unusual weighing equipment must be examined by each agency. 
Reciprocity between FGIS and NBS is nearing the final stages for grain hopper scales and automatic weighing systems. California is currently reviewing the FGIS checklist prior to comment.

The appropriate form for testing for compliance with the permanence requirement (G-S.5.2.5) is currently being evaluated by both NBS and California. The draft proposal contains three options for consideration by the Task Force. It is the intent to actively work toward mutually agreeable guidelines by the concerned agencies.

In the interim, California will continue to require a field permanence test for larger scales. NBS does not perform such tests. Consequently, if a request for prototype examination is received by OWM without a request for joint certificate of approval with California, OWM will not include a field permanence test as part of its examination. California Type Approval would require the field permanence test to be performed in addition, but would not repeat the OWM tests. The same is true of FGIS where their requirements are different from Handbook 44 .

To receive a Report of Test from two or more agencies based upon a single examination, it is necessary that a letter (or copies) be sent to each agency which is to issue a Report for the device being submitted for type approval. The letters must be received before an examination is initiated to permit the agencies to discuss the device before the testing begins so that specific tests can be conducted to satisfy any particular needs of the other agencies. Reciprocal Peports of Test will not be issued retroactively on any devices.

It is hoped that the Task Force will be able to facilitate resolution of different requirements between agencies so that ultimately the standard examination conducted by one agency will automatically satisfy the requirements of another agency. Changes to Handbook 44 and State and Federal regulations will ultimately be necessary to achieve this goal.

If reciprocity is desired between California and NBS on a device submitted for type approval, digital weighing equipment may be submitted to either NBS or California. If the equipment is submitted to NBS and is one for which permanence testing (to certify compliance with G-S.5.2.5) is necessary in the field, then the device will have to receive this field test in California since OWM is not presently set up to perform such tests.

Hopper scales and automatic weighing systems for which joint NBS and FGIS approval is desired should normally be submitted to FGIS for examination.

A joint meeting of the Task Force on National Type Approval and the S\&T Committee is scheduled to be held January 14 from 1:00 - 5:00 p.m. as part of the interim meetings of the NCWM. The NCWM interim meetings will be held January $14-17,1981$ at Texas A\&M University, College Station, Texas. All interested parties are invited to attend and participate. Any topics may be brought up for discussion. Specific topics scheduled for discussion are: 
1. Current operation of type approval programs and the reciprocity program

2. Establishment of specific goals and directions for a national type approval program

3. Review of comments, checklists, and procedures

4. Discussion of permanence test requirements.

Written comments on the above items are encouraged and should be sent to the Office of Weights and Measures by January 1, 1981 so they may be summarized and available to the Task Force members at the interim meetings. 


\section{TABLE OF CONTENTS}

I. Status of Draft Criteria and Procedures

II. Checklist for Digital Weighing Equipment

III. Checklist for Retail Motor Fuel Devices

IV. Checklist for Electronic Hopper Scale

V. Procedure for Dynamic Testing of Bulk Weighing Systems and Automated Batch Controllers

A. Test of Static Scale to be Used for Checkweighing

B. Procedure for the Dynamic Test

VI. Permanence Performance Testing for Scales and Electronic Cash Registers

VII. Laboratory Permanence Test for Scales

VIII. Performance Tests for a Vehicle Scale and Axle Load Weighing Element

IX. Performance Tests for Platform Scales Except Vehicle, Railroad, Livestock, and Digital Counter (Bench)

Scales

X. Performance Tests for Digital Counter (Bench) and Price Computing Scales

XI. Guideline: Use of Error Weights on Digital Scales

XII. Test of a Digital Scale Using Error Weights 



\section{Status of Draft Criteria and Procedures}

\section{Checklist for Digital Weighing Equipment}

This is an update and revision of two previous checklists that have been used in type approval examinations over the past three years. The revision was discussed in detail by California, Federal Grain Inspection Service (FGIS), and the Office of Weights and Measures (OWM) representatives at a meeting in August. This draft is currently under review by all parties. The draft is considered near completion.

\section{Checklist for Retail Motor Fuel Devices}

This is the second draft of the checklist. The initial draft was reviewed at the August meeting. This draft is currently under review. It is expected to be expanded and undergo further revisions.

Checklist for Electronic Hopper Scales

This draft contains type approval criteria and considerations specifically related to electronic hopper scales. These considerations are in addition to the Checklist for Digital Weighing Equipment. The relationship of this checklist with the checklist used by FGIS in its type approval examination will be reviewed. This is the second draft. Further revisions are expected.

Procedure for Dynamic Testing of Bulk Weighing Systems and Automated Batch Controllers

This test is currently being utilized in California on aggregate weighing systems. This item is included to obtain comments on the potential benefit of the test and the feasibility of the procedure.

Permanence Performance Testing for Scales and Electronic Cash Registers

This draft summarizes the current testing needed to verify the permanence of a device necessary to fulfill reciprocity considerations in type approval examinations. It identifies which devices are subject to permanence tests. Comments are requested on the three different tolerance applications and time periods involved. Ultimately, one set of parameters will be selected and applied to weighing equipment.

Laboratory Permanence Test for Scales

The permanence test for some devices can be performed in the laboratory. The procedures are the basis of agreement between California and OWM to achieve reciprocity in laboratory tests. The procedure has been used for many years in OWM laboratory permanence tests.

Performance Tests for a Vehicle Scale and Axle Load Weighing Element

The test procedure outlined in the draft is the test method that has been used by OWM for many years. The subsequent permanence tests have been added to achieve reciprocity. 
Performance Tests for Platform Scales Except Vehicle, Railroad, Livestock, and Digital Counter (Bench) Scales

The test procedure outlined in the draft is an abbreviated version of the testing currently performed in OWM examinations. The test procedure has been shortened in recognition of the permanence test that has been added to achieve reciprocity.

Performance Tests for Digital Counter (Bench) and Price Computing Scales

This draft explains when a laboratory permanence test may be performed and also provides a field permanence test when the laboratory test cannot be performed. It is expected that the laboratory test will normally be performed.

Guideline: Use of Error Weights on Digital Scales

This draft reflects the philosophy that a digital scale may be tested either by direct reading or by using error weights. If error weights are used then the one-half scale division permitted for direct reading is not applied. The draft gives guidelines of when error weights should be used. so that the size of the scale division will not hinder evaluation of the scale performance and when direct reading may be used for increased efficiency without affecting the evaluation of device performance.

Test of a Digital Scale Using Error Weights

This paper explains how to test a digital scale using error weights. The paper is near its finished form. 
Lab Test $\square$

Conducted by:
Field Test

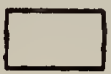

Date:

Location:

Manufacturer: Name

Address

Zip

Telephone

Representative

Prototype device

or Production device

Equipment

Type: Mechanical

(e.g. lever)

Electromechanical

(e.g. lever-tronic)

Electronic

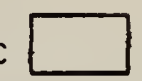

If electronic, type of technology

(e.g. microprocessor)

Capacity $\times \mathrm{d}_{\mathrm{d}}$ $1 b$ $\mathrm{kg}$

Weighing Element
Indicating Element

Control Element

Printing Element

If applicable: platform size

number of sections

section capacity

Load Cell Data

Type:

Tension

Mode1

Quantity

Excitation Voltage

Live Load $(\mathrm{mV})$
Compression

Serial No.

Manufacturer

Serial No.

\section{焉}

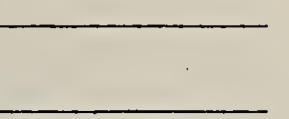

Model 
Standard Features

Optional Features

1.

2.

1.

2.

3.

3.

4.

4.

5.

5.

6.

6.

Examination Checklist - Digital Electronic Scales

Scale Code Requirements

(Code references are for Handbook 44 and California regulations)

Zero Indication

Complies?

Code References S.1.1. G-S.5.1. CA 3011.1.1.

avoirdupois/metric selection (1b/kg)

External

Internal

Not applicable

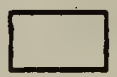

1. The width of zero must be $\leq 1.0 \mathrm{~d}_{\mathrm{d}}$ avoirdupois: Record actual zero width metric: Record actual zero width Yes No N/A other units: unit zero width Yes No N/A Yes No N/A

2. A + or - sign should not appear when the scale is indicating zero.

avoidupois

metric

other units

Yes No N/A

Yes No N/A

Note: A plus sign for positive numbers is discouraged since an unsigned number is considered to be positive.

3. If a center of zero light is provided, it must define the center of zero to $\pm 1 / 4 d$ or better. (The center of zero light itself is optional.)

Yes No N/A 
4. The zero indication must consist of at least the following minimum indications, as appropriate:

a. One digit to the left and all digits to the right of a decimal point

Yes No N/A

b. If a decimal point is not used, at least one active decade plus any constant (fixed) zeros

Examples: Capacity
$25 \times .011 \mathrm{~b}$
$5000 \times 11 \mathrm{~b}$
$100000 \times 201 b$
$0.001 \mathrm{~b}$
$01 \mathrm{~b}$
$001 \mathrm{~b}$

Minimum zero indication

Yes No N/A

5. Any of the following methods may be used to indicate a negative balance condition.

a. Displaying negative numbers

b. Blanking the display

Note 1: This method cannot be used if the device also blanks the display to indicate over-capacity and the load condition of the load-receivingelement is not evident to the operator; e.g., a hopper scale where the operator cannot see the load condition (empty or fu11) of the hopper. It is recommended that the indicator also have an annunciator to indicate "power on" so the operator does not think the power has been lost.

Note 2: If the device is equipped with a tare capability, when in the net weight display mode, the device must indicate negative net weight values when the gross weight is less than the tare value.

c. A display of a symbol which cannot be interpreted as a quantity value; e.g., -, ----, EEEE, Err, E S-1, etc.

Note: Flashing zeros or -00 is not acceptable.

d. Display of complement weight values in excess of scale capacity; e.g., for a $120000 \times 201 b$ capacity scale, if the scale is $201 \mathrm{~b}$ behind zero, the display may indicate $999980 \mathrm{lb}$.

Yes No N/A

Yes No N/A

Note: This method may be used only when the indication is not confusing. 
Code Reference S.1.4.

The zone of uncertainty must be $\leq 0.3 \mathrm{~d}$. Test under the following conditions and record the width of the zone of uncertainty.

a. Near zero: avoirdupois metric other units

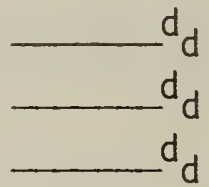

b. Near capacity: avoirdupois metric other units

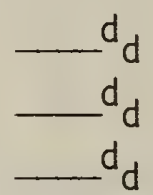

\section{Capacity Indication}

\section{Code References \\ S.1.4.1. \\ CA 3011.1 .4 .1}

A scale is not permitted to indicate or record weight values when the gross load exceeds $105 \%$ of the nominal scale capacity. This requirement applies regardless of how the scale is manipulated to achieve this condition. Flashing weight values above capacity is not acceptable as an overload indication. Compliance should be tested for both indicating and recording weight values under the following conditions in all weight units.

Nominal system capacity $1 \mathrm{~b}$ $\mathrm{kg}$

\section{other units}

1. With the scale at zero load, record the last number displayed before blanking or giving the overload indication.

$1 b$ $\mathrm{kg}$ other

Yes No N/A

2. Enter the maximum tare value permitted. Does the scale give the overload indication within the specified gross load limit?

Yes No N/A

3. If the scale can rezero loads up to scale capacity, rezero a load that exceeds $5 \%$ of the scale capacity. Does the scale give the overload indication within the specified gross load limit?

$\begin{array}{lll}\text { Yes } & \text { No } & N / A \\ \text { Yes } & \text { No } & N / A \\ \text { Yes } & \text { No } & N / A \\ \text { Yes } & \text { No } & N / A \\ \text { Yes } & \text { No } & N / A \\ \text { Yes } & \text { No } & N / A\end{array}$

Complies? 
4. If the scale limits the amount that can be rezeroed in one push button zero operation but the operation can be repeated several times, rezero weight of approximately $5 \%$ of the scale capacity. Does the scale give the overload indication within the specified gross load limit?

Yes No N/A

5. If the scale rezeros itself after a power interruption, place a load on the scale that will be rezeroed and interrupt the power. Under this new zero, does the scale give the overload indication within the specified gross load limit?

Yes No N/A

6. A scale should not indicate or record weight values if the load receiving element rests on its protective movement limiting stops.

Values Displayed, Temperature Conditions

Code Reference S.1.4.2.

Devices should not indicate or record weight values until the operating temperature necessary for accurate weighing and a stable zero balance condition has been attained. Compliance with this section will be determined under the following conditions;

1. The requirement will not be applied to a device that is activated at the time of installation.

2. The automatic zero setting mechanism, if provided, will be permitted to be operational at the time of test.

3. The tests for compliance with this requirement should be performed at temperatures between $40-80^{\circ} \mathrm{F}$.

Either condition a or b must be met.

a. Is power maintained to the load cells at all times? Yes No N/A

b. Is the device accurate when power is turned on and the scale is operational?

Yes No N/A

Test method: The test will simulate a normal weighing operation; it is not based upon a complete test of the scale. First, if the scale has a power switch, turn on the power to the scale. As soon as the scale is operational, place a test load of one-half scale capacity 
on the load receiving element. If a sufficient number of test weights are not available to reach one-half scale capacity, use the maximum amount of test weights available. Place the weights on the scale over a short period of time to approximate normal loading as close as possible. Leave the weights on the scale for the time used in a normal weighting operation. The weight indication must be within tolerance. Remove the test load. The scale must return to zero within the minimum tolerance to be applied to the scale. For direct reading of a digital scale, this will usually be a tolerance of one division. The scale must maintain a stable zero balance. If desired, the test load may be reapplied to the load receiving element.

Equipment that is designed to maintain power to the load cell when the power switch for the weight display is turned off will be considered to comply with the requirement.

\section{Customer's Indications - Digital Computing Scales}

Code References S.1.6.3 CA 3011.5.2.

1. If the operator's side of the scale indicates the net weight, unit price, and total price, the customer's side must be similarly equipped.

Yes No N/A

2. Customer price displays must be in unit price terms only; i.e., fractional pricing (e.g., 1/4 1b or 1/2 1b) or multiple pound (e.g., $3 \mathrm{lb} / \$ 1.00$ ) is not permitted.

Yes No N/A Note 1: California permits 1/4 1b and 1/2 1b pricing. Note 2: Multiplier keys are permitted.

$\frac{\text { Provision for Sealing Adjustable Components }}{\text { Con Electronic Devices }}$

Are electronic scale calibrating controls (other than the fine zero balance adjustment) or access to such controls supplied with provision for sealing?

Note: Handbook 44 permits the use of the pressure sensitive seals in additon to lead and wire seals. (See the definition of security seal in the General Code.) California and FGIS require the use of lead and wire seals.

Describe how the device is to be sealed. 


\section{Zero Load Adjustment - General}

Code References S.2.1.1. . CA 3011.2.1.1.

Complies?

Indicate the zero adjustment method.

(a) Tool operated zero adjustment

(b) Push button zero

(c) Power switch zero adjustment

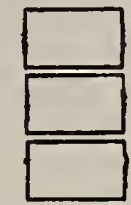

1. If the device has push button or power switch zero, does it comply with the motion detection requirements of S.2.1.2.?

Yes No N/A

2. If a digital scale has an analog zero adjustment mechanism, is the range of the analog zero $1 d$ or less?

Yes No N/A

(G-S.2. Fraud Considerations)

3. For counter (bench) and computing scales used in direct sales, does motion detection prevent rezeroing when the platform is being raised or pushed down by hand?

\section{Automatic Zero Setting Mechanism (AZSM)(Zero Tracking)}

Code Reference S.2.1.3.

Indicate the status of the AZSM capability.

(a) No AZSM capability

(b) AZSM is always operational

(c) AZSM may be activated or deactivated by an external switch

(d) AZSM may be activated or deactivated by an internal switch or selected by programming at the time of installation

(e) The size of the AZSM operature is selectable

If the device has an AZSM capability, record the size of the aperture.
(a) avoirdupois
(b) metric
(c) other units

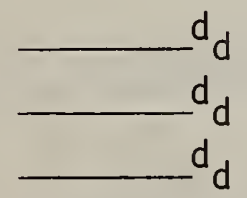

Does the size of the aperture comply with S.2.1.3. for the intended application? 
Note: For devices falling under S.2.1.3. (a), AZSM may be operable with the device at a gross load zero, a net load zero, or a negative net weight indication resulting from a tare weight entry, and the scale at zero gross load. AZSM should not be operable on any hopper scale. Devices falling under S.2.1.3 (b) and (c) are permitted to have AZSM operable only at a gross load zero.

AZSM is not to be operational when the scale is displaying a positive weight value.

\section{Zero-Load Adjustment - Monorail Scales}

Code Reference S.2.1.4.

1. Means must be provided for setting the zeroload balance and any tare value less than $5 \%$ of the scale capacity to within $0.02 \%$ of scale capacity.

Yes No N/A

2. For an in-motion system, the conditions above must be automatically maintained.

Yes No N/A

\section{Tare Mechanism}

Code Reference S.2.1.4.

1. The tare mechanism shall operate only in the direction of underregistration; i.e., a negative number should not be taken as tare.

Yes No N/A

Test method for push button (platter) tare:

Rezero (using the zeroing mechanism) a small

load and remove the load. This will result in a behind-zero indication. Attempt to take this value as tare using the push button. It should not be accepted as tare.

2. A tare entry of zero should not result in an indication that tare has been taken.

Yes No N/A (G-S.5.7. Consideration)

3. A minimum net load of 20 divisions should be required before a computing scale automatically clears a tare entry.

Yes No N/A

(G-S.5. Consideration: This is not a requirement.) A prepackaging or computing scale that takes tare to the same resolution as the displayed scale division, for example $0.01 \mathrm{lb}$, may result in a 
significant bias on packages utilizing the same

tare material. For example, suppose a large

number of packages is being prepared and the actual weight of the tare is $0.024 \mathrm{lb}$. If the scale can only take tare as $0.021 \mathrm{~b}$, the packages will have a bias toward short weight of $0.004 \mathrm{lb}$. This is readily detectable on the $51 \mathrm{~b} \times .002 \mathrm{1b}$ even arm balance used to check small packages.

It is recommended that scales used for prepackaging be able to take tare to $\pm 1 / 4$ of the displayed scale division. This would reduce package errors due to the rounding of the tare weight.

Record whether or not the push button tare is taken to a higher resolution than the displayed scale division.

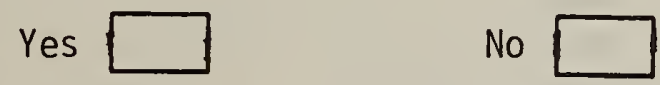

Test method: Place a load on the scale so that the scale is near the breakpoint on the upper half of the scale division. Weights representing less than $1 \mathrm{~d}_{\mathrm{d}}$ will probably have to be used. Tare off this load. Determine if the net weight zero reference point is near the center of the net weight zero indication. If it is, the tare was taken to a resolution better than $1 d_{d}$.

Leveling Indicating Means - Portable Scales

Is the device equipped with a level indicator as standard equipment?

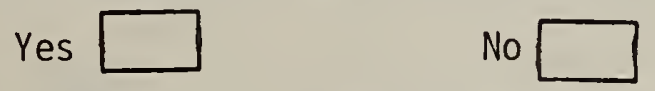

1. If not, does the device comply with the provisions of S.2.3.?

The test procedure is given in "Performance Tests for Digital Counter (Bench) and Price Computing Scales".

2. Is the level-indicating means readily observable without mechanical disassembly that requires the use of tools?

Yes No N/A 
3. Portable scales must have a means of leveling the device;e.g., adjustable legs.

Yes No N/A

\section{Damping Means}
Code References
S.2.4.
CA 3011.2 .4 .

Is the device equipped with an effective means for damping oscillations?

Yes No N/A

\section{Electronic (Recording) Elements Code Reference S.2.4.1.}

Is the electronic indicating element equipped with or may it be equipped with a recording element?

Yes

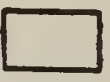

No

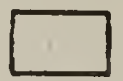

If yes, does it comply with the motion detection requirements of S.2.3.1.? Test for both large and small $\left(10 d_{d}\right)$ changes in weight.

Yes No N/A

Design of Load - Receiving Elements - Drainage
Code References
S.3.2.
CA 3011.3 .2 .

If the load-receiving element is designed to receive wet commodities, is it designed to drain effectively?

Yes No N/A

\section{Design of Weighing Elements - Antifriction Elements}

Code Reference S.4.1. CA 3011.4.1.

1. Are frictional effects reduced to a minimum in the weighing element?

Yes No N/A

2. For platform scales: Is interference between platform and frame prevented?

Yes No N/A

\section{Multiple Load - Receiving Elements \\ Code Reference S.4.3. CA 3011.4.3.}

Can the indicating or recording element be coupled to two or more load-receiving elements with independent weighing systems?

Yes

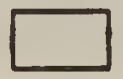

No

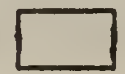


If yes, does the indicating element:

(a) Automatically indicate which loadreceiving element is in use?

Yes No N/A

(b) Prohibit the activation of any load-receiving element not in use?

Yes No N/A

\section{Marking Requirements - Nominal Capacity \\ Code References S.6.1. CA 3011.6.1.}

1. The nominal capacity by minimum division in all externally selectable weight units is to be clearly and conspicuously marked adjacent to the weight display.

Yes No N/A

2. The marking must be permanent.

Yes No N/A

Note: Permanence of the capacity marking is less stringent than for the identification badges. Ideally, this information should be silk-screened on the front panel adjacent to the weight display. Occasionally this information is applied at the time of installation: An external decal stating the capacity by division size may be used provided it is likely to remain on the device under normal use. If a decal is damaged or becomes illegible it must be replaced. A DYMOtype tape label is not considered acceptable for production devices. The capacity by minimum division may be stated on a strip of paper provided it is placed inside the device adjacent to the weight display and is protected from external influences that could damage the paper or obliterate the lettering.

3. The capacity by division size must be marked for all externally selectable weight units; e.g, , in both pounds and kilograms.

4. Does the scale display weight values up to and including its marked capacity?

Yes No N/A

Note 1: A scale must display the weight value equal to its rated capacity. For example, a scale that can display to only 199.9 1b cannot be marked $200 \times 0.11 \mathrm{~b}$

Note 2: Scales with variable resolution must be marked with the weight ranges and corresponding division sizes.
Example:
1b) $\times 19$
b) $\times 2 \mathrm{~g}$
$(0.002$
$(0.005$
$6-15 \mathrm{~kg}$
$(33 \mathrm{lb}) \times 5 \mathrm{~g}$
$(0.01$ 
Note 3: This requirement applies to digital

indicating elements and to customer's indications on computing scales. Remote displays which provide the only weight indication must also be marked. The customer weight display provided for scales interfaced with electronic cash registers (ECRs) must be marked. Weight displays which are built into ECRs must also be marked. Large remote customer ("scoreboard") displays have not been required to meet the marking requirements because the markings probably could not be read from a customer's position. In this case the operator's weight display must be properly marked.

\section{Marking - Special Applications}

Code References S.6.2. CA 3011.6.2.

The philosophy of this requirement is that devices which are designed specifically for special applications are to be marked for the application. This is intended to prevent the device from being used in an application where it is not suitable. Although the requirement is written for prepackaging scales, the philosophy has been extended to other applications as mentioned below.

1. Prepackaging scales are to be marked "For Prepackaging Use Only" or with a similar statement.

Yes No N/A

2. Weight classifying scales are to be marked "For Rate Determinations Only" or with a similar statement.

Yes No N/A

3. Digital scales indicating in ounces (division size of not more than $0.1 \mathrm{oz}$, preferably $0.05 \mathrm{oz}$ ) are to be marked "For Meal Portions Only" or with a similar statement.

Yes No N/A

Livestock, Vehicle, and Railway Track Scales

Code References S.6.3. CA 3011.6.3

The section capacity of a livestock, vehicle, and railway track scale must be marked on or adjacent

to the identification badge on the indicating element. Yes No N/A 


$$
\frac{\text { Marking Requirements - Weighing Elements }}{\text { Code References S.6.4. CA 3001.1. }}
$$

Weighing elements not permanently attached to an indicating element must be clearly and permanently marked with:

(a) The name, initials, or trademark of the manufacturer.

Yes No N/A

(b) The manufacturer's designation that positively identifies the pattern or design

Yes No N/A

(c) The nominal capacity of the weighing element.

Yes No N/A

Note 1: To be permanent, the badge should be a metal or plastic plate that is riveted, welded, or attached by an adhesive so that a tool is required to remove the badge. Bolts or screws are not acceptable. Because of the potential for damage to a badge, a foil badge is not acceptable.

The badge may be mounted on protected surfaces such as the side of the weighing element behind a ramp or under a cover plate. Access to the badge should be available with a minimum amount of effort.

Note 2: Small capacity weighing elements may be marked with a capacity that is greater than the indicator is capable of displaying. This may occur with an ECR with a $251 \mathrm{~b}$ display capacity and a weighing element rated at $30 \mathrm{lb}$. This is acceptable but the weights and measures official may conduct a shift test using a test load of one-half the rated capacity of the weighing element. For example, this would be $15 \mathrm{lb}$.

General Code Requirements

\section{Identification}

Code References G-S.1. CA 3001.1.

All equipment except weights is required to be marked on an exterior surface visible after installation with the following information: 
(a) Is the badge visible after installation? (See note 1)

Yes No N/A

(b) Is the badge permanent? (See note 2)

Yes No N/A

(c) The name, initials, or trademark of the manufacturer.

Yes No N/A

(d) The manufacturer's designation that positively identifies the pattern or design.

Yes No N/A

(e) A nonrepetitive serial number.

Yes No N/A

Note 1: Equipment is to be marked on a surface that is visible after installation in a normal manner. The bottom of a device (or the back if it is wall mounted) is not an acceptable surface. The back of a device is acceptable if it is portable. Portable is defined as weighing less than $35 \mathrm{lb}$ and having a length and width of $24 " \times 18$ " or less.

Note 2: The badge must be permanent. It may be a metal or plastic plate attached with pop rivets or adhesive or other means. Removable bolts or screws are not permitted. A foil badge may be used provided it is destroyed in any attempt to remove the badge. Additionally, the printing on a foil badge must be easily read and not easily obliterated by rubbing with a relatively soft object (i.e., wood of a pencil).

Note 3: Remote weight displays have not been required to have serial numbers because they typically do not have any electronics used in analysing the weight signal received from the weighing element. The remote display is required to have the manufacturer's name or trademark and model designation. Similarly, the various "slave" modules in a modular point-of-sale system; e.g., printer, keyboard module, and cash drawer have not been required to have a serial number because they do not have any "intelligence". Only the electronics modules which control the "slave" modules have been marked with a serial number. This is considered satisfactory and in compliance with Handbook 44. 
Code Reference G-S.2., G-S.5.1, CA 3001.2., 3001.5.1.

\section{Power Interruptions}

After a momentary (maximum of ten seconds) power interruption, an indicating element should either return to zero, display the weight value that was displayed before the power failure assuming the load has not changed, or display an error signal or meaningless information which cannot be interpreted as a weight value and which requires operator intervention to return the scale to operation. The meaningless information may be ----, EEE, $6 C E 7$ etc. If the scale returns to an incorrect weight value, that is a weight value different by more than one division from the weight value displayed before the power interruption, the device is considered to facilitate fraud.

Test method: If the scale is equipped with AZSM (zero tracking), track off several divisions of weight.

Place a load on the scale and note the weight that is displayed. Simulate a power failure by pulling the power plug. Do not interrupt the power for more than ten seconds. Return power to the device and record below the manner in which the scale returns to operation.

Repeat the test by using the power switch to interrupt the power.

Record the method used to return the scale to operation.

Power Plug

1. Device returns to zero

Yes No N/A

2. Returns to the previously displayed weight value

Yes No N/A

3. Displays a meaningless display or error signal which requires operator intervention.

Yes No N/A

4. Displays an incorrect weight value

Does not N/A comply

Power Switch

1. Device returns to zero

Yes No N/A

2. Returns to the previously displayed weight value

Yes No N/A

3. Displays a meaningless display or error signal which requires operator intervention.

Yes No N/A

4. Displays an incorrect weight value 


\section{Facilitation of Fraud - Tare Operation}

Code References G-S.2., G-S.5.1., G-S.5.2.2., G-S.5.6., CA 3001.2, 3001.5.1

Indicate the type of tare capability available:

Complies?

No tare capability

Keyboard tare
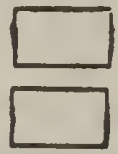

Pushbutton tare

Digital tare
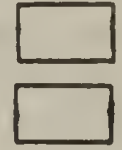

Thumbwheel tare

1. Devices equipped with a tare capability, except for electronic cash registers, are required to provide a clear indication that a tare value has been entered. If the tare value can be cleared when a load is on the platform, a clear indication that the tare value has been eliminated must be provided. Several options exist to comply with this requirement. The primary purpose of this requirement is that devices which do not provide GROSS and NET indications must provide a lighted legend or annunciator such as TARE ENTERED or similar statement to indicate a tare value has been entered.

At least one of the following methods must be used to indicate a tare value has been entered. Indicate which method is used.

(a) A separate continuous display of tare is provided. Yes No N/A

(b) The device can display the GROSS, TARE, and NET weight with proper display identification of this information.

Yes No N/A

(c) The device can display the GROSS and NET weight with proper display identification of this information.

Yes No N/A

(d) The display indicates only the net weight and a NET legend or annunciator appears when a tare weight is entered.

Yes No N/A

(e) A lighted legend or annunciator of TARE ENTERED or similar statement is used to indicate that a tare value has been entered and the display indicates the net weight.

Yes No N/A

(f) An entry of zero should not activate the TARE ENTERED annunciator.

Yes No N/A 


\section{Complies?}

2. If a device is equipped with push button tare and keyboard tare, the entry of either tare value must automatically clear any previous tare entry; i.e., they cannot be additive.

Yes No N/A

3. The tare value plus the net weight must always equal the gross weight.

Yes No N/A

Recorded Representations of Gross, Tare, and Net Weight

There are two primary considerations concerning the printing of gross, tare, and net weight values.

First, the recorded values of the gross, tare, and net weight must be mathematically correct; that is,

$$
\text { gross weight }=\text { net weight }+ \text { tare weight. }
$$

Secondly, the recorded values must agree with the indicated values. If these requirements cannot be met, a printer cannot be used with the indicating element.

(a) Is the tare weight entry consistent with the displayed scale division in both pounds and kilograms?

Yes No N/A

(b) If no, the device is not permitted to interface with a printer.

Yes No N/A

\section{Push Button Tare}

1. If a device is equipped with an external push button zero;i.e., it does not require a tool to activate the tare operation, and the device is to be used in direct sales, then the push button tare must have a motion detection capability of meeting S.2.1.2. requirements.

Yes No N/A

2. If the device has a gross/net switch, the push button tare must be inhibited when the gross weight is being displayed.

Yes No N/A

3. If the device has a gross/tare/net switch, the push button tare must be inhibited when the gross weight is being displayed.

Yes No N/A 
4. (a) Does push button tare operate to the full capacity of the scale?

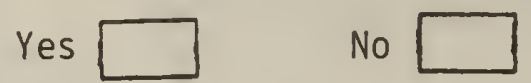

(b) If no, the push button tare must be inhibited when the gross weight exceeds the tare capability.

Example: If the scale can only take 9.99 lb as tare, when a gross load of $10.00 \mathrm{lb}$ is placed on the scale, no tare should be taken when the tare key is pressed.

Yes No N/A

For information purposes, test if the push button tare value is taken to a weight value smaller than the displayed scale division.

Test method: Apply a load to the scale so that the scale indication is on the high side of the displayed weight division but below the zone of uncertainty. It probably will be necessary to use weights of less than one scale division to achieve this conditon. Take this weight as tare by pressing the push button tare key. Test if the net weight zero reference point is in the center of the displayed net zero indication. If it is, the scale takes tare to a value smaller than the displayed tare division. If the net zero reference point is still on the hgih side of the net zero division, tare is taken to the displayed scale division.

Tare is taken to a value smaller than the displayed scale division

Tare is taken to the displayed scale division

\section{Keyboard Tare}

Keyboard tare should be operable only with no load on the platform unless there is a separate display of tare values or the tare values are recallable and verifiable.

1. One of the following conditions must be met for keyboard tare entries:

(a) The device has a tare display entirely separate from the weight display which continuously indicates the entered tare weight.

Yes No N/A

(b) The device has a selectable tare display mode activated by key or switch and

(i) tare values may be entered only when the tare mode is selected or

Yes No N/A

(ii) tare values may be recalled and verified at any time

Yes No N/A

(c) Entries are permitted only when there is no load on the platform

Yes No N/A 
(d) The device indicates gross weight only with the tare or net weights appearing on a printed weight ticket.

Yes No N/A

Note: Under items (a), (b), and (d), the tare value may be entered when a load is on the scale platform.

2. Are keyboard tare value entries consistent with the displayed scale division in both pounds and kilograms?

Yes No N/A

If NO then one of the following conditions must be met.

(a) A tare value that is not consistent with the displayed scale division is automatically rejected.

Yes No N/A

(b) The tare weight entry must be rounded to the nearest displayable scale division.

Yes No N/A

(c) (i) A tare value entered and displayed in values less than the value of a displayed scale division, the tare value must actually be taken to the smaller weight unit; i.e., the tare value must be valid.

Yes No N/A

(ii) The number of tare divisions must not exceed 20000.

Yes No N/A

( $i$ ii) The value of the tare division must be equal to $1 / 2$ or $1 / 5$ the value of the displayed scale division.

Yes No N/A

Test method: To test if the tare value is taken to a value smaller than the displayed scale division, first place a load on the scale that results in a stable display of a weight value. Next, increase the tare value in the smallest tare increments until the net weight display just enters the zone of uncertainty. If the zone of uncertainty is smaller than the smallest tare increment, increase the tare value until the displayed net weight changes to the next lower number. At this point increase the load on the scale by a fraction of a division, for example $0.3 \mathrm{~d}_{\mathrm{d}}$ or $0.6 \mathrm{~d}_{\mathrm{d}}$. This should result in a stable net weight display. Increase the tare value in increments of the smallest tare value. If the smaller tare values are meaningful, the additional tare required to reach the zone of uncertainty or breakover point should equal the additonal load applied to the scale.

(d) If tare is taken to a value smaller than the displayed scale division, the net weight must be indicated in values consistent with the displayed scale division for the gross weight: e.g. if the scale capacity is $100000 \times 201 \mathrm{~b}$ and the tare entry is $101 \mathrm{~b}$, the net weight must still be displayed to the nearest $201 \mathrm{~b}$ division. 


\section{Digital Tare}

Digital tare is the capability that each time the digital tare key is pressed, one displayed scale division is taken as tare.

1. The digital tare division must equal the displayed scale division.

Yes No $N / A$

2. (a) The digital tare entry may automatically clear any previous tare entry or

Yes No N/A

(b) Digital tare may add to a push button or keyboard tare entry

Yes No N/A

3. Digital tare entries are permitted only under the conditions described in Keyboard Tare item 1.

Yes No N/A

Which condition is met?

(Circle) a b(i) b(ii) c d

\section{Thumbwheel Tare}

There are several considerations applicable to the use of thumbwheel tare on a digital indicating element. First, if numbered thumbwheels are used to set a tare value, it is presumed that the thumbwheel value is the tare display. In this case the indicator is assumed to have gross and net weight display modes. It is conceivable that the indicator displays only the net weight but the following discussion will assume gross and net weight display capabilities. Possible variations considered are whether a printer is used, whether or not a pound/kilogram conversion capability is provided and the requirements applicable if the pound/kilogram conversion capability is internally or externally available. The mathematical agreement of the gross, tare, and net weight is of primary importance.

I. Indicator equipred with thumbwheel tare but no $\mathrm{lb} / \mathrm{kg}$ conversion.

Condition 1 or 2 must be met.

1. The tare division is consistent with the displayed scale division.

If yes, the indicator may be interfaced with a printer for direct sales. 
Note: If the display has a fixed zero, the thumbwheel indication must also have a fixed zero. The fixed zero may be silk screened adjacent to the thumbwheel provided it has the same size and spacing as the thumbwheel digits.

2. (a) The tare weight is taken to values smaller than the displayed scale division.

Yes No N/A

If yes, this device is not permitted to interface with a printer for direct sales.

(b) If yes, then the following conditions must be met.

(i) The tare value must actually be taken to the smaller weight unit;i.e., the tare value must be valid. (See the test method under Keyboard Tare item $2(\mathrm{c})$. )

Yes No N/A

(ii) The number of tare divisions must not exceed 20000 .

(iii) The value of the tare division must be equal to $1 / 2$ or $1 / 5$ the value of the displayed scale division.

Yes No N/A

(iiii) The net weight must be indicated in values consistent with the displayed scale division for the gross weight (See example in Keyboard Tare item $2(d)$. )

Yes No N/A

II. Indicator equipped with thumbwheel tare and an internal $1 \mathrm{~b} / \mathrm{kg}$ conversion switch

Condition 1 or 2 must be met.

1. The tare division is consistent with the displayed scale division and the thumbwheel division size must be physically changed when the display units are changed to maintain the consistent division size.

Yes No N/A

If yes, the indicator may be interfaced with a printer for direct sales.

2. (a) The tare weight is taken to values smaller than the displayed scale division.

Yes No N/A

If yes, this device is not permitted to interface with a printer for direct sales.

(b) If yes, then the conditions of Thumbwheel Tare item I.2. must be met. 
III. Indicator equipped with thumbwheel tare and an external $\mathrm{lb} / \mathrm{kg}$ conversion switch

It is not possible to have numbered thumbwheels which are consistent with the displayed scale division in both pounds and kilograms because under G-S.5.3.1. Dual Indications, comparable weight values for the division size must be used. Consequently, recorded weight values cannot meet the two requirements of agreeing with the displayed weight values, and the gross, tare, and net weights being in mathematical agreement when numbered thumbwheels are used. The reason for this is that the net weight must be indicated to the displayed scale division used in the gross weight mode. Due to the inability to meet these requirements when numbered thumbwheels are used, a printer cannot be used with an indicating element using this technology.

Since it is frequently desirable to have a printed record of transactions, a printer can be interfaced with an indicator with an external pound/kilogram conversion switch if the thumbwheels (or dial wheels) are not numbered. If thumbwheels wi thout numbers are used, several conditions must be met. The conditions result from G-S.5.1. and G-S.2. The conditions are listed for two types of indicators; (1) those with the ability to indicate gross, tare, and net weight by selecting the proper display mode and (2) those indicators that can display the gross and net weight.

A. Indicators with gross, tare, net display capability.

1. No numbers should appear on the thumbwheels (or dials).

Yes No N/A

2. Tare entries are accepted or updated only when the thumbwheel position is changed when the tare weight is being displayed. If the position of the thumbwhee 7 is changed when the indicator is in the gross or net display mode, the tare value should not change. It is acceptable to automatically switch to the tare display mode when the position of a thumbwheel is changed if all switch sectings and annunciators convey correct information. It is the change in thumbwheel position when the tare weight is displayed that activates the update of the tare value, not merely the display of the tare value.

Yes No N/A 
3. When the weight units are changed by using the external $\mathrm{lb} / \mathrm{kg}$ conversion switch, the tare value must be converted to the comparable value in the selected units; e.g., $10000 \mathrm{lb}\left(\mathrm{d}_{d}=20 \mathrm{lb}\right)$ becomes $4540 \mathrm{~kg}\left(\mathrm{~d}_{\mathrm{d}}=10 \mathrm{~kg}\right)$. The tare value should update to the actual switch position numbers when a thumbwheel position is changed when the tare value is being displayed.

Yes No N/A

4. The tare weight division is consistent with the displayed scale division.

Yes No N/A

B. Indicators with gross/net display capability.

1. No numbers should appear on the thumbwheels (or dials).

Yes No N/A

2. Tare entries are accepted or updated only when the net weight is displayed and the gross load is zero so the tare weight can be verified. The tare weight value will appear as a negative net weight. If the position of the thumbwheel is changed when the indicator is in the gross weight display mode or when the scale is under a load, the tare value should not change. If the gross load is zero and the display is indicating the gross weight, it is acceptable for the display mode to automatically switch to the net display mode when a thumbwheel position is changed. It is the change of the thumbwheel position when the gross load is zero and the net weight is displayed that activates the update of the tare value, not merely the display of the tare as a negative net weight.

Yes No N/A

3. When the weight units are changed by using the external $1 \mathrm{~b} / \mathrm{kg}$ conversion switch, the tare value must be converted to the comparable value in the selected units; e.g., $100001 \mathrm{~b}\left(d_{d}=201 \mathrm{~b}\right)$ becomes $4540 \mathrm{~kg}\left(\mathrm{~d}_{\mathrm{d}}=10 \mathrm{~kg}\right)$. The tare value should update to the actual switch position numbers when a thumbwheel position is changed when the gross load is zero and the tare weight is being displayed as a negative net weight.

Yes No N/A

4. The tare weight division is consistent with the displayed scale division.

Yes No N/A 
Code References G-S.2., CA 3001.2

1. Printers must be automatically inhibited when the following information is being displayed by the indicator:

a. Dead-load verification values

Yes No N/A

b. R-calibrated values and other test values

Yes No N/A

c. Electronic display verification sequences

Yes No N/A

2. Manipulation of the power cord or printer cable must not influence the indicated or recorded weight values.

Yes No N/A

3. Operation of associated or non-associated electronic equipment must not affect digital indications.

Yes No N/A

4. Use of any operational functions or options should not facilitate fraud.

Yes No N/A

5. Does the equipment, through its characteristics and design, prevent fraudulent operation or inaccurate weight values.

Yes No N/A

\section{Permanence-Materials, Design, and Construction}

Code References G-S.3., CA 3001.3

Do the materials, design, and construction make it probable that:

1. Accuracy will be maintained?

Yes No N/A

2. Operating components will function as intended?

Yes No N/A

3. Adjustments will remain permanent?

Yes No N/A

Interchange or Reversal of Parts

Code References G-S.4., CA 3001.4

Are parts that may be interchanged or reversed in normal field assembly:

1. Constructed so that reversal will not affect performance? or

Yes No N/A

2. Marked to indicate proper position.

Yes No N/A 
Code References G-S.5.1., CA 3001.5.1.

1. The minimum divisions of both indicating and recording elements must be in values of 1,2 , or 5 times $10^{\text {n }}$ where $\mathrm{n}$ is an integer; e.g., $0.1,0.2$, or $0.5 ; 1,2$, or $5 ; 10$, 20 , or 50 ; etc.

Yes No N/A

2. A push button zero may operate in the gross, net, or tare display mode if the gross load is rezeroed and all other indications change to the proper value with respect to the new gross weight zero reference point.

3. A fixed zero cannot appear after a decimal point; i.e., all decades after a decimal point must be active.

Yes No N/A

4. A printer must record the same number of decimal places as indicated in the display. Example: A digital indicator may display weight values to $0.011 \mathrm{~b}$ and $0.005 \mathrm{~kg}$. The printer must record a weight value in pounds to $0.01 \mathrm{lb}$; not to $0.0101 \mathrm{~b}$.

5. The optional center of zero light must be inhibited at all displayed weight values other than zero.

Yes No N/A

6. Upon return to gross load zero, a device may automatically display other information; for example, it may cycle the time, date, and zero indications, provided that the display of the other information occurs only when the scale is at zero, the zero indication can be displayed, or is displayed as part of the cycled information. The values must be clearly defined. The scale must display weight values or give an out of balance indication whenever the scale is out of zero balance. The scale must immediately indicate weight values when a load is applied to the scale.

7. Computing scales that automatically clear the tare value after a weighing must require a minimum net load of $20 \mathrm{dd}$ before the tare value will automatically be cleared.

Note: This is to prevent the tare weight from being cleared when the tare is removed from the scale to be filled. It also prevents accidental clearing of tare if the net weight goes slightly positive as the operator removes the tare from the scale. The minimum net load of $20 d_{d}$ is taken from the OIML minimum load for Class III scales. 
3. Non-weighed item information must be automatically cleared from the display following computation of the transaction total.

Yes No N/A

4. The addition of tax charges to the transaction total should not increase the "item" count or display.

Yes No N/A

Computing Scales that Display Retail Price Information After Load Removal

For digital price computing scales that retain and display accumulated price information following removal of the load:

1. Accumulated price information may be held following removal for 15.0 seconds or less.

Yes No N/A

2. The computing scale must automatically return to its zero reference.

Yes No N/A

3. The computing scale must automatically return to a "non-hold" or active mode at any time a new unit-price is entered during a "hold" period.

Yes No N/A

4. It is acceptable for the scale to initiate label printing during stable loaded platform conditions.

Yes No N/A

5. If the scale initiates label printing or "print command" during the "hold" period, it must automatically return to an active mode and print the correct weight and price information for the new load conditions.

Yes No N/A

\section{Menu Service Scales}

The weight units may be in ounces.

1. The scale division must be less than or equal to $0.1 \mathrm{oz}$. (A scale division of $0.05 \mathrm{oz}$ is preferred.)

Yes No N/A

2. If the weight unit is ounces, the scale must be marked "For Menu Service Only" or with a similar suitable statement.

Yes No N/A

Are all indicating and recording elements appropriate in design and adequate in amount?

Yes No N/A

Are primary indications and recorded representations clear, definite, and accurate?

Yes No N/A 


\section{Digital Indication and Representation}

Code References G-S.5.2.2., CA 3001.5.2.2.

1. Are digital elements designed so that:

a. All digital values of like value in a system agree with one another?

Yes No N/A

b. Any digital value coincides with its associated analog value?

c. All digital values round to the nearest minimum division?

2. a. Does the digital display utilize partial or "half" segments in the most significant decade (MSD)?

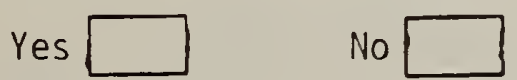

b. If yes, the device is required to meet one of the following two conditions

(i) Blank the complete display when the digit " $7 "$ would appear in the MSD when the minus sign is also being displayed.

Yes No N/A

(ii) The minus sign must be masked to provide separation between the "-" and the digit "7" in the MSD.

Yes No N/A

\section{Computing Scales with Multiple Sales Accumulation Capability}

Note: Computing scales which have both the multiple sales accumulation capability and price-look-up capability will be considered to be electronic cash registers. They will be expected to meet all the requirements applicable to cash registers and to issue a sales receipt similar to that of a cash register.

For digital price computing scales with the ability to accumulate multiple weighed and non-weighed item price transactions:

1. The scale is required to have an "item" count or "item display" to continuously indicate the number of items totalized for any transaction.

Yes No N/A

2. Non-weighed item information must be automatically prohibited from being entered when the scale is at any non-zero reference. 
Code References G-S.5.2.3:, CA 3001.5.2.3.

1. Are graduations, indications, or recorded representations uniform in size and character?

2. Are subordinate graduations, indications, or recorded representations appropriately designed or portrayed?

Yes No N/A

Graduations, Indications, and Recorded Representations - Values, Dual Indications

Code References G-S.5.2.4., G-S.5.3.1., CA 3011.5.2.4.

1. The lower case "kg" must be used on display panels and keys when the symbol for kilogram is used.

Yes No N/A

2. The lower case "kg" should be used for printing when possible. The upper case "KG" is an acceptable symbol for kilogram if the lower case "kg" cannot be printed.

Yes No N/A

3. Any other metric symbols must comply with the table given under G-S.5.6.1.

Yes No N/A

4. A printer interfaced with an indicator with an external $\mathrm{lb} / \mathrm{kg}$ conversion switch must automatically record the weight unit in which the indicator is displaying weight values.

Yes No N/A

Note: Preprinted weight tickets stating the weight unit are acceptable for indicators capable of displaying only one weight unit or which have an internal $\mathrm{lb} / \mathrm{kg}$ conversion switch.

5. An indicator with an external $1 \mathrm{~b} / \mathrm{kg}$ conversion switch must identify the units in which the display is indicating.

a. The unit should appear adjacent and to the right of the weight display.

Yes No N/A

Note: Adjacent means within a distance equal to the width of the active display.

b. Front panel mounted toggle switches are required to be adjacent and to the right of the weight display and must have the unit identified by an LED or other lighted annunciator. (The position of the toggle switch alone is not considered an adequate identification of the unit in use.)

Yes No N/A 
c. Front panel mounted toggle switches must identify the switch position and function by a lighted annunciator; e.g., an LED with the silk-screened legend Gross or Net.

Yes No N/A

d. If back-lighted push button type operational controls are to define the display mode (e.g., net, gross, $1 \mathrm{~b}, \mathrm{~kg})$, these controls are required to be located adjacent to the weight display with no other controls between the display and the descriptive keys. Yes No N/A

e. When the power switch is also used as a means for rezeroing the device, it is required to be marked as
(i) Power/Zero or
(ii) On-Off/Zero

Yes No N/A

Yes No N/A

6. If the system has an external $1 \mathrm{~b} / \mathrm{kg}$ conversion switch, the system must indicate and record in comparable values in pounds and kilograms. Example: $20 \mathrm{lb}$ and $10 \mathrm{~kg}$, $5 \mathrm{lb}$ and $2 \mathrm{~kg}$.

Yes No N/A

7. Devices used in direct sales must have only one $1 \mathrm{~b} / \mathrm{kg}$ selector switch which converts both the weight display and tare values into comparable weight values.

Yes No N/A

8. Are graduations, indications, or recorded representations properly defined by figure, word, or symbol?

Yes No N/A

\section{Graduations, Indications, and Recorded Representations - Permanence}

Code References G-S.5.2.5., CA 3001.5.2.5.

Are all graduations, indications, or recorded representations permanent and legible?

Yes No N/A

Values of Graduated Intervals or Increments

Code References G-S.5.3., CA 3001.5.3.

Are all graduations, indications, or recorded representations uniform throughout the series?

Yes No N/A

\section{Repeatability of Indications}

Code References G-S.5.4., CA 3001.5.4.

Does the device repeat, within prescribed tolerances, its indications and recorded representations for:

1. Increasing load tests?

Yes No N/A 
Complies?

2. Decreasing load tests?

Yes No N/A

3. Repeatability of indications including zero?

Yes No N/A

4. Shift or section tests?

Yes $\mathrm{NO} \quad \mathrm{N} / \mathrm{A}$

5. (This is not a Handbook 44 requirement.)

a. If the power supply voltage can be varied, is the device accurate when the voltage is $100 \mathrm{~V}$ and $130 \mathrm{~V}$ ? (The OIML specification is $+10 \%$ and $-15 \%$ of $117 \mathrm{~V}$.)

Yes

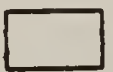

No<smiles>C1CCC1</smiles>

b. If no, over what voltage range does the device operate? (Do not exceed the limits of $100 \mathrm{~V}$ and $130 \mathrm{~V}$.

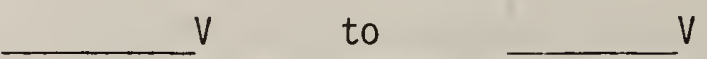

6. One of the following conditions should be met.

a. Does the scale return to zero within the minimum applicable tolerance after the load is removed?

Yes No N/A

b. If no, test the scale for return to zero using the test method given below. The scale should return to zero at least 9 out of 10 times.

Yes No iN/A

Test method: Rezero the scale. Place a load of approximately one-half scale capacity on the load receiving element. Leave the load on the scale for the time used in a normal weighing operation. Remove the load. The scale should return to zero (direct reading), not merely within the applicable minimum tolerance. Reapply the load several more times in a manner approximately normal use.

\section{Money Values, Mathematical Agreement}

Code References G-S.5.5., CA 3001.5.5.

Are all recorded and indicated digital money values in mathematical agreement with their associated quantity representations to the nearest one cent?

Yes No N/A 
The following sample calculations are suggested for price computing scales.

Net Weight $\times$ Unit Price $=$ Total Price

Correctly

$0.101 \mathrm{~b}$

$\$ 0.04$

$0.107 \mathrm{~b}$

$\$ 0.05$

$\$ 0.0040$

$\$ 0.0050$

$0.101 \mathrm{~b}$

$\$ 0.15$

$\$ \quad 0.0150$

$0.311 \mathrm{~b}$

$\$ 0.85$

$0.317 \mathrm{~b}$

$\$ 0.89$

$0.321 \mathrm{~b}$

$\$ 0.83$

$0.321 \mathrm{~b}$

$\$ 0.89$

$1.517 \mathrm{~b}$

$\$ 0.07$

$\$ 0.70$

$1.511 \mathrm{~b}$

$1.517 \mathrm{~b}$

$\$ 7.00$

$2.501 \mathrm{~b}$

$\$ 0.69$

$2.501 \mathrm{~b}$

$\$ 79.29$

$\$ 198.225$

$2.541 \mathrm{~b}$

$\$ 0.79$

$\$ 2.0066$

$2.541 \mathrm{~b}$

$\$ 0.86$

$2.541 \mathrm{~b}$

$\$ 3.99$

$2.541 \mathrm{~b}$

$\$ 4.25$

$\$ 2.1844$

$\$ 10.1346$

$\$ 10.7950$

$2.54 \mathrm{1b}$

$12.541 \mathrm{~b}$

$\$ 99.99$

$\$ 2.25$

$\$ 253.9746$

$\$ 28.2150$

$12.541 \mathrm{~b}$

$\$ 99.99$

$\$ 1253.8746$

$\$ 1.83$

$20.671 \mathrm{~b}$

$\$ 0.59$

$24.517 \mathrm{~b}$

$\$ 0.89$

$\$ 27.5049$

Rounded

$\$ \quad 0.00$

$\$ \quad 0.00$

or

$\$ 0.01$

$\$ 0.01$

or

$\$ \quad 0.02$

$\$ 0.26$

$\$ 0.28$

$\$ 0.27$

$\$ 0.28$

$\$ 0.11$

$\$ 1.06$

$\$ 10.57$

$\$ 1.72$ or

$\$ 1.73$

$\$ 198.22$

or

$\$ 198.23$

$\$ 2.01$

$\$ 2.18$

$\$ 10.13$

$\$ 10.79$ or

$\$ 10.80$

$\$ 253.97$

$\$ 28.21$

or

$\$ 28.22$

$\$ 1253.87$

$\$ 27.50$

$\$ 12.20$

$\$ 21.81$ 


\section{Recorded Representations}

Code References G-S.5.1, G-S.5.6.

CA $3001.5 .1,3001: 5.6$

Complies?

1. Are all recorded values printed in a digital format?

2. Gross weight must equal the net weight plus the tare weight.

Note: Handbook 44 does not require that a device print gross, tare, or net weight, but some weighmaster laws require recording all three weight values.

3. If the indicating element has a memory so that it is able to weigh incoming vehicles, loaded or empty, store this weight information, weigh the outbound vehicle, empty or loaded, and compute the net weight, the net weight must be computed with the proper sign and the recorded weight values must be clearly and properly identified.

4. Multiple tare memory registers:

See the appendix for criteria

\section{Magnified Graduations and Indications}

Code References G-S.5.7., CA 3001.5.7.

Does the device use optical magnification of the indications?

Yes

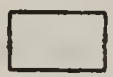

No

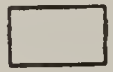

If yes, does the magnified image conform to all appropriate requirements?

\section{Marking, Operational Controls, Indications and Features}

Code Reference G-S.6

1. Thumbwheels must be identified.

Yes No N/A

Note: Keyboards or keypads do not have to be identified although the individual operating keys must be marked; e.g., $0,1,2, \ldots, 9$

2. Keys or operator controls visible to the customer during a direct sale should be marked with words or symbols so the customer can understand the transaction.

Yes No N/A 
Note: Keys and controls that are visible only to the operator and for the operator's use only, need only be marked with symbols that are understood by the operator or by someone who has been trained to use the device.

3. All operational controls on the back panel of a device should be identified. Interfacing plugs for load cell or printer connections and other plugs are to be identified by words, symbols, or codes.

Yes No N/A

4. All operational controls, indications, and features including switches, lights, displays, pushbuttons, and other features, shall be clearly, and definitely identified.

Yes No N/A

Lettering of Markings and Instructions

Code References G-S.7., CA 3001.6

Are all required markings and instructions distinct and easily readable?

\section{Suitability of Equipment}

Code References G-UR.1.1., CA 3004.1.1.

Is the device suitable for service including the elements of its design, weighing capacity, computing capability, etc.?

Yes No N/A

\section{Selection Requirements - Environment}

Code References G-UR.1.2.

Is the equipment suitable for the environment in which it

is intended to be used including:

1. Electromagnetic and radio-frequency interference generated by electromechanical equipment, portable hand-held ratio transmitters, citizens band transmitting equipment, etc.?

Yes No N/A

2. Hostile environment including extreme temperature and moisture conditions?

Yes No N/A 


\section{Installation Requirements}

Code References G-UR.2.1.; CA 3004.2.1 Complies?

1. Is the device installed in accordance with the manufacturer's instructions?

Yes No $\mathrm{N} / \mathrm{A}$

2. Is the device to be installed at a fixed location? Yes

No

3. If yes, is it so installed that neither its operation no its performance are adversely affected by any characteristic of the foundation, supports, or any installation detail:

Yes No N/A

Comments: 


\section{Prototype Criteria \\ Multiple Tare Memory Registers \\ for Direct and Indirect Sales}

The use of microprocessors has made it possible for several tare values to be entered into a digital indicator by keyboard entries or using push-button tare. The proper operation of an indicator having multiple tare memory registers depends upon whether the indicator is used in direct or indirect sales and whether a printer is used in these situations. In normal circumstances the indicator will be able to indicate the gross, tare, and net values. A distinction will be made between tare entries during normal weighing operations and tare values that are entered in a separate programming operation.

I Direct Sale -- No Printer - Tare Entries in Normal Weighing Operation

1. The tare values are to be entered only when the display is in the tare display mode so the entries can be verified. The display may automatically return to the gross or net mode after a time delay.

2. Each tare value must be recalled and verified before each weighing so the customer can verify the tare value.

II Direct Sale -- Printer - Tare Entries in Normal Weighing Operation

1. The printer must print the gross, tare, and net values as a continuous sequence so the values are documented and verifiable. If the gross or tare weight is obtained by weighing the inbound weight of a vehicle, the inbound weight should also be recorded on the weight ticket at the time of the inbound weighing.

2. The digital indicator is not required to display the tare weight before each weighing because the weight ticket documents the transaction.

II Direct Sale -- Printer - Preprogrammed Tare

This is applicable to computing scales having preprogrammed tare incorporated with price look-up capabilities. This feature has not been observed in any other systems except point-of-sale systems.

1. The tare weights can only be entered when the scale is in a special programming mode.

2. The scale is not required to display or print the gross or tare weight provided the net weight is recorded. The rationale for this is that the weights and measures official can verify the accuracy of the preprogrammed tare weights during inspections.

IV Direct Sale -- No Printer - Preprogrammed Tare

The considerations stated in item III apply. 
$\checkmark$ Indirect Sale -- No Printer - Tare Entries in Normal Weighing Operation

1. The tare values are to be entered only when the display is in the tare display mode so the entries can be verified. The display may automatically return to the gross or net mode after a time delay.

2. Each tare value must be recalled and verified before being used for the first time in a series of weighings. Once selected, the tare weight may be retained and used without reverification for all the weighings requiring the selected tare weight. The tare weight may be retained until it is replaced when a new tare value is recalled.

VI Indirect Sale -- Printer - Tare Entries in Normal Weighing Operation

The conditions stated in item $V$ apply. Only the net weight is required for printing when the weight ticket or label is the basis of the transaction.

VII Indirect Sales -- No Printer - Preprogrammed Tare

Each tare value should be verified before being used for the first time in a series of weighings. This can be achieved by displaying the tare value as a negative net weight when the gross load on the scale is zero. Once selected, the tare weight may be retained and used for all the weighings requiring the selected tare weight. The tare weight may be retained until it is replaced when a different tare value is recalled.

VIII Indirect Sales -- Printer - Preprogrammed Tare

The conditions stated in item VII apply. Only the net weight is required for printing when the weight ticket or label is the basis of the transaction. 
Lab Test II Field Test I_I DATE:

Type Approval Test ivuaber:

LOCAT ION :

SPECIFICATION REQUIREMENTS

Schematics Subnitted: Yes I_

No II

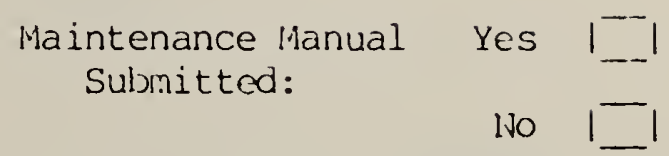

MAIUEACTURER INFORMATION

Company Name:

Address :

Phone : 1 )

PROTOTYPE DEVICE(S)

MODEL NUMBER

1. Retail Motor Fuel Dispenser

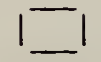

1.

2. Remote Console

2.

3. Computing Register

3.

4. Ticket/Receipt Printer

4.

5.

5.

\section{INTERFACE $(S)$}

TECHNOLOGY

1. Remote Console

Mechanical

Electronic

Analog Display

Digital Display

Postpay

Pleset Money

Preset Volume 
1. Device Configuration:

Single Product

Dual Product

Multiple Product

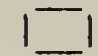

II

1
Self Contained Single

Self Contained Dual

Remote Single

Remote Dual

2. Reset:

Manual

Electric
Key

Time Delay

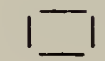

I

3. Totalizer:

Mechanical: Volune

1 \$ Sales

Electronic: Volume

$1 \quad \$$ Sales

(Mechanical Volume Totalizer Required on Dispensers) Shift Totals

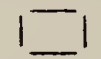

4. Pulser:

Mechanical
Electronic
Pulse Rate (Gallon Display)

Pulse Rate (Honey)
Pulses Per Gallon Pulses Per Gallon

Liter 1

Pulses Per Penny 
5. Display:

Segment Check

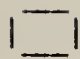

Volume:

Minimum Indication

$$
\begin{array}{lllll}
\text { Gallons } & 0.1 & .01 & .001 \\
\text { Liters } & .01 & .001
\end{array}
$$

Fixed Decinal

1

Floating Decimal

Selective Decimal

Maxisurn Volume Display Gallons Liters

Volurne Display Suppression:

___ Gallons None

Unit Price:
Maximum $\$$ /gallon.
Maximum $\$$ /liter.

Total Sale:

Maximurn Display $\$$

6. Gallon/Liter Conversion:

None

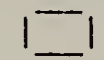

New Chip

Cut Jumper wire I_

Switch position I I

Metric Gear Box I- 
7. Allocation Control:

None

Money

Volume

8. Battery Power Back-up:

Yes II No II

(Required for digital indicating dispensers)

9. Other Standard Features:

A.
B.
C.

10. Other Optional Features:

A.

B.

C.

11. Definitions:

Allocation Control - A means of setting a dispenser or console for a maximum volune or total sale delivery for rationing purposes.

Electronic Pulser - A pulse transmitter utilizing electronic means such as light beam interruption to provide pulse counts.

Mechanical Pulser - A pulse transmitter utilizing mechanical means such as reed switches, gears, and magnets to provide pulse counts.

Fixed Decimal - Decimal point that is fixed and permanently placed, not intended to be repositioned.

Floating Decinal - Decimal point that shifts its position automatically during the operation of the device, such as shifting from y9.999 gallons to 100.00 gallons when volune exceeds 100.00 gallons.

Selective Decinal - Decimal point that can be electronically shifted by a switch, by cutting a jumper wire, or replacing a jumper wire, etc. 


\subsection{GENERAL CODE REQUIREMENTS}

Code Section

G-S. 1 .

$\mathrm{G}-\mathrm{S} .2$

G-S.3.

\section{Specifications}

\section{Compliance}

1. Identification. All equipment shall be clearly and permanently marked (requires the use of a tool in order to remove) on an exterior surface visible after installation with the following information:

A. Name, initials, or trademark of the manufacturer.

Yes No N/A

B. The manufacturer's designation that positively identifies the pattern or design.

C. The nonrepetitive serial number.

Yes No N/A

2. Facilitation of Fraud

A. Electronic yispenser - Is the dispenser incapable of accepting or computing a unit price change while the dispenser is "on"?

B. Is correct data retained on dispenser and transmitted to remote indicators, if used in conjunction with remote indicators, under following power failure/interruption conditions?

1. Power failure/interruption during deliveries.

2. Power failure/interruption between Yes No N/A transactions.

3. Power failure/inceruption between Yes No N/A delivery and shut-off.

3. Permanence. Equipment shall be of such materials, design, and construction as to nake it probable that, under normal service conditions:

A. Accuracy will be maintained.

Yes No N/A

B. Operating parts will continue to function as intended, and

Yes No N/A

C. Adjustments will remain reasonably permanent.
Yes No N/A

Yes No N/A
Yes No N/A 
Code Section

$G-5 \cdot 4$

G-S.5.

G-S.5.1.

Specifications

Compliance

4. Interchange or reversal of parts.

Yes No N/A

5. Indicating and recording elements.

A. Appropriate in design and adequate in anount.

1. Are the maximun money and volume indications appropriate for its intended usc?

2. If volume indications are suppressed when dispenser is turned on, is the suppression less than

0.009 gallon? How much suppression? gallon/liter.

3. If a digital indicator dispenser is used in conjunction with a prepay remote console is the volume displayed on dispenser to the nearest 0.001 gallon?

a. If a digital indicator dispenser displays volume to the nearest 0.01 gallon and is used in conjunction with a prepay remote console, does the dispenser deliver at least the prepaid dollar amount for all total sales up to the capacity of the indicators?

Unit Price vs. Preset Examples:

\begin{tabular}{cccc}
$\begin{array}{l}\text { UNIT } \\
\text { PRICE }\end{array}$ & $\begin{array}{c}\text { PRESET } \\
\$\end{array}$ & $\begin{array}{c}\text { SHOULD } \\
\$\end{array}$ & $\begin{array}{c}\text { DELIVER } \\
\text { VOL }\end{array}$ \\
\hline 1.319 & 8.00 & 8.01 & 6.07 \\
1.319 & 14.00 & 14.01 & 10.62 \\
1.419 & 5.00 & 5.01 & 3.53 \\
1.169 & 10.00 & 10.01 & 8.56 \\
\hline
\end{tabular}


b. If a digital indicator dispen- Yes No N/A ser displays volume to the nearest 0.01 gallon, is there mathematical agrecment at all volumes and unit prices?

Mathematical Agreement Example:

\begin{tabular}{llcll}
$\begin{array}{l}\text { UNIT } \\
\text { PRICE }\end{array}$ & $\times$ & $\begin{array}{c}\text { INDICATED } \\
\text { VOLUME }\end{array}$ & $=$ & $\begin{array}{r}\text { TOTAL SALE } \\
\pm 1 / 2\end{array}$ \\
\hline 1.319 & $X$ & 6.06 & $=$ & 7.99 \\
1.319 & $X$ & 6.07 & $=$ & 8.01 \\
1.319 & $X$ & 10.61 & $=$ & 13.99 \\
1.319 & $X$ & 10.62 & $=$ & 14.01 \\
1.419 & $X$ & 3.52 & $=$ & 4.99 \\
1.419 & $X$ & 3.53 & $=$ & 5.01 \\
1.169 & $X$ & 8.55 & $=$ & 9.99 \\
1.169 & $X$ & 8.56 & $=$ & 10.01
\end{tabular}
B. Clear, definite and accurate. Yes. No N/A
C. Easily read under normal operating Yes No N/A conditions.

G-S.5.2. 6. Graduations, indications and recorded representations.

G-S.5.2.1.

A. Analog - Designed to advance

Yes No N/A continuously.

$G-S .5 .2 .2$

B. Digital - Test at least

individual deliveries for each mode

(postpay, preset money, preset volume).

1. All like digital money values Yes No N/A must be in agreenent.

2. All like digital volume indications must agree except volume indications of: 
a. Dispensers and postpay/prepay Yes No N/A (preset money mode) remote consoles must agree within $\$ 0.005 \div$ unit price.

Example: Unit Price $=\$ 1.329 / \mathrm{gal}$. $\$ 0.005 \div \$ 1.329 / \mathrm{gal}=0.0038$ gal.; rounded off to 0.004 gallon maximum disagreement between dispenser and remote console.

b. Digital indicating dispensers used in conjunction with a remote console in preset volume mode:

1. Must indicate at least the Yes No N/A volume preset on the console, and

2. Must be in mathematical agreeement with total sales indications $+\$ 0.005$. (Volume $x$ Unit Price $=$ Total Sales $\pm \$ 0.005$.

3. Totalizers. On several individual Yes No N/A deliveries, check the accuracy and ageement of the dispenser mechanical totalizer with the dispenser and console digital totalizer displays.

4. Digital values agree with associated analog value to the

Yes No N/A nearest minimum graduation.

G-S.5.2.3.

C. Size and Character.

1. Uniform in size and character.

Yes No N/A

2. Subordinate graduations, indiYes No N/A

$6-5 \cdot 5 \cdot 2 \cdot 4$

D. Values adequately defined.

Yes iro $N$ ! $A$ 
$G-5.5 \cdot 2 \cdot 5$

G-S.5.3.

G-S.5.4.

G-S.5.5.
E. Permanence. tions, or recorded representations must be permanent and legible.

7. Values of graduated intervals or increments. Uniform throughout any series.

8. Repeatability of indications.

9. Money values, mathematical agreement. Any recorded money value and any digital money value indication must be in mathematical agreement with its associated quantity (volume) representation or indication to the nearest one cent.

FORMULA: Unit Price $X$ Indicated Volume $=$ Total Sale $+1 / 2$ Cent

Check mathematical agreement under following conditions:

A. At various flow rates, including nıximum and minimum.

B. Snapping nozzle on and off several times during delivery.

c. At several unit prices including low price and maximum pricing capability of computer.

D. Turn dispenser off during delivery with nozzle open.

$G-5.5 .7$

10. Magnified graduations and indications. conform to all requirements for gradua$t i o n s$ and indications.

$\mathrm{G}-\mathrm{S} .5 .8 . *$

11 .

Agreement of indications. Analog indications intended to indicate the same amount of volume shall not differ by more than the acceptance tolerance of the device.

$\mathrm{G}-\mathrm{S} .6$
12. Marking, operational controls, indications, and features shall be clearly and definitely identified.
Yes No N/A

Yes No N/A

Yes ho in/A

Yes No N/A

Yes No N/A

Yes No N/A

Yes No N/A

Yes ino $N / A$

Yes No N/A

Yes No N/A 
G-S.7.

G-UR.1.1

G-UR-1.2.

15. Enviromment. Suitable for environment of its intended use, including hostile weather and radio frequency interference.

G-UR.2.1.

16. Installation.

A. Installed in accordance with manufacturer's instructions.

B. Perforinance not adversely affected by any detail of the installation.

G-UK.2.1.1

C. Identification and all required inarkings readily observable.

G-UR.2.3.

G-UR.3.3.

G-UR.3.4. instructions shall be permanent, distinct and easily read.

14. Suitability of equipment for intended service with respect to elements of its design.

18. Position of equipment. A device equipped with a primary indicating element shall be positioned so the indications may be accurately read and the masuring opera$t$ ion observed from some reasonable "custoner" position. (Driver's position inside vehicle being fueled and attendant's position during fueling.)

19. Responsibility. Money-operated (coiris,
13. Lettering. Required markings and

Yes No N/A

Yes No N/A

Yes No N/A

Yes No N/A

Yes No N/A

Yes No N/A tokens, dollar bills) devices shall have the following information clearly and conspicuously displayed:

A. The method for return of monies paid when the product or service cannot be obtained.

B. Name, address and phone number of the local servicing agent for the device.
Yes No N/A

Yes No N/A 
Code Section

Specifications

Cornpliance

S. 1 .

S.1.1.

S.1.1.1.

S.1.1.2.1.

S.1.1.3.

S.1.1.4.

20. Design of indicating and recording elements and of recorded representations.

A. Primary elements.

1. The device shall be equipped with a primary indicating element and nay also be equipped with a primary recording element.

2. The device shall indicate, and record if equipped to record, its deliveries in terms of liters or gallons and decimal or fractional equivalents.

3. Value of sinallest unit of indicated delivery shall not exceed the equivalent of one pint.

4. Advancement of indicating and recording elements.

a. Shall be susceptible of advancement only by the mechanical operation of the device (except for clearing the device to zero).

b. May be cleared by advancing to zero if the advancing movement canmot be stopped until zero is reached, or in the case of indicating elements only, the elements are automatically obscured until the elements reach the currect zero condition.

S.1.2.1.

B. Graduations length. Varied so that they may be conveniently read.

Yes iNo N/A Yes No N/A

Yes No N/A Yes Wo N/A Yes No Y

Yes No N/A

S.1.2.2.

C. Graduations width.

1. 0.008 inch or incre wide.

Yes No N/A 
2. In any series of graluations, thu: Yes No N/A graduation width shall be not greater than the width of the minimum clear interval between graduations.

3. Main graduations shall be no more Yes No N/A than 50 percent wider than subordinate graduations.

\section{$\mathrm{s}: 1.2 .3$}

D.

S.1.3.

S.1.3.1.

\section{E. Indicators.}

\section{Symmetry - Index shall be syn- metrical with respect to its associated graduations.}

S.1.3.2.

\section{s. $1.3 \cdot 3$}

\section{No less than $0.04 \mathrm{inch}$.}

2. Length.
a. The index shall reach to the Yes No iv/A. finest graduations; or
b. If the indicator and gradua- Yes. No N/A tions are in the sane plane, the distance betwcen the in- dicator end and the ends of the graduations shall be no more than 0.04 inch.

Yes No N/A

Yes Nu N/A 
S.1.3.4.

S.1.3.5.

S.1.4.1.

S.1.4.2.

$\mathrm{S} .1 .4 .3$

S. $1.4 \cdot 4$.

5.1 .4 .4

$5 \cdot 1 \cdot 4 \cdot 4 \cdot 1$.
4. Clearance - Between the index and

Yes No iN/A the graduations shall be no more than 0.06 inch.

5. Parallax - Reduced to practicable minimurn.

F. Indication of delivery. Shall show automatically its initial zero condition and amount delivered up to nominal capacity of the device.

G. Return to zero.

Yes No N/A

H. Display of unit price and product identity.

I. Money-Value computations.

1. Full-computing type.

Yes No N/A

2. Analog money value indications shall not differ from the mathematically conputed money value (Quantity $x$ Unit Price = Sales Price), for any delivered quantity, by an amount greater than one-half the value of the money value division.

3. Moncy-Value divisions analug shall be as follows:

a. Not more than 1 cent at all unit prices up to and including $\$ 1.00$.

b. Not more than 2 cents at all unit prices greater than $\$ 1.00$ up to and including $\$ 3.00$.

c. Not more than 5 cents at all unit prices greater than $\$ 3.00$.

4. Money-Value Divisinns, Difital. A computing type device with digiYes ino $N / A$ tal indications shall comply with the requirements of paragraph G-S.5.5. Money values, mathematical agreement, 
and the total price computation shall be based on quantities not exceeding, 0.01 gallon intervals for devices indicating in inch-pound units and 0.02 liter for devices indicating in metric units.

S. 1.4 .5 .

S. 2 .

S.2.1.

S.2.2.

s.2.3.

S.2.4.
J. Travel of indicator on lubricant devices. The relative movement of the indicator and graduations shall be not less than one inch per one pint of delivery.
Yes No N/A

\section{Design of measuring elements.}

A. Vapor elimination - Automatic vapor/air Yes No N/A eliminator with vent lines made of metal tubing or other suitable rigid material.

B. Provision for sealing any ineasurement element and adjusting mechanisin.

Yes No N/A irectional flow valves shall be automatic in operation.

Yes No N/A.

D. Stop mechanism.

1. Position secure from impact or direct pressure.

Yes No N/A

2. Adjustable to provide for deliveries within prescribed tolerances.

3. If two or inore slops may operate selectively to permit deliveries of predetermined amounts:

a. The position for the proper setting shall be accurately defined.

Yes ino N/A

b. Inadvertent displacenent fiun position shall be obstructed.

Yes No N/A

c. The deliverv for which the device is set shall be conspicuously indicated.

Yes No $N / A$

Yes lio $\therefore / \therefore$ 
S.2.5.1.*

$\mathrm{S} .2 .7 .1$.

S.3.

$5.3 \cdot 1 . *$

5.3 .5 .
E. Zero-set-back interlock.

1. After device is turned of $f$, prevents subsequent delivery until indicators have returned to their correct zero positions.

2. Starting lever shall be in shut off position and zero-set-back interlock engaged before nozzle can be returned to its designed hanging position, or what appears to be its intended hanging position from a reasonable customer position.

3. Where more than one dispenser is Yes No N/A comnected to single pump there shall be an automatic control valve which prevents fuel from being delivered unt il the indicating elements have been returned to their correct zero position and engaged.

F. For lubricant devices only, other than meter types, it shall become inoperable or give a conspicuous and distinct warning when the level of lubricant becomes so low as to endanger the accuracy of ineasurement.

22. Design of discharge lines and discharge line valves.

A. Diversion of measured 1 iquid. No means shall be provided to allow any measured $l$ iquid to be diverted from the measuring chamber or from the discharge line. (See Code Section 3.30.S.3.1.* for discharge outlets $1-1 / 2$ inches or larger, and fueling trucks.)

B. Discharge valve may be installed in the discharge line only if the device is of the wet-hose type.
Yes iNo N/A

Yes No N/A

Yes No N/A

Yes No N/A
Yes No N/A 
S.3.6.

S. $3.7 . *$

S.4.1.

23. Marking requirements - Limitation of use

UR.1.1.

UR.1.1.1.

24. Length of discharge hose. No longer

UR.2.

UR.2.1.

UR.2.2. infornation shall be clearly and permanently stated on the device.

\section{USER REQUIREMENTS} than 18 feet (except for marinas and airports - hose shall be as short as practical, no longer than 50 feet).

C. Antidrain valve. A wet-hose, pressure-type device shall have an effective antidrain valve incorporated in the discharge valve or adjacent thereto.

D. Nozzles for use on retail motor fuel devices shall be equipped with an effective antidrain valve.

Yes No iN/A Yes No iN/A

Yes No. N/A

Yes No N/A

Yes No N/A 
This test report does not include indicating and recording devices. These are included in the Weighing Device Test Report - General Information. A complete. system test report for electronic hopper scales includes the appropriate sections of that report as well as the report below:

Field Test No:
Date :

Loc ation:

\section{SPECIFICATION REQUIREMENTS}

Schematics

Submitted

Yes $\square$ No -

MANUFACTURER INFORMATION

Company Name:

Address :

Phone

Company Contact:

\section{PROTOTYPE DEVICE INFORMATION}

Model Number :

Capacity

Minimum Increment:

LOAD CELL DATA

Manufacturer :

Model Number :

output $(\mathrm{m} \vee \mathrm{N})$ :

Type of Cell:

Number of Cells:
Operating

Manual

Yes $\square$ No $\square$

Maintenance

Manual 


\section{Identification/Marking}

G-S.1

G-UR.2.1.1

$\mathrm{S} .6 .4$

1. Name, initials or trademarks of the inanufacturer.

Yes No

2. Manufacturer's model designation that positively identifies the pattern or design.

Yes No

3. Non-repetitive serial number.

Yes No

4. Nominal capacity of scale.

Yes No

5. Identification/marking information clearly and permanently marked.

Yes No

6. Identification/marking information must be visible after installation. Access to badge must be visible Yes No with minimum amount of effort.

Note: Item 2 must be a specific nodel number.

A. series number is not acceptable.

(Example: Model 500 not Series 500.)

Note: In Item 5, permanent means metal plate riveted in place. Foil tags are not acceptable.

\section{Installation and Design of Weighing Elements}

G-UR.2.1

3004.2 .1

G-UR.1.2

UR. 2.3

3004.2 .3

G-UR.2.3

3004.2 .3
1. Using the engineering drawings, schematics, and installation instructions, is the device installed properly.

Yes No

2. Suitability of equipment for the environment in which it will normally be used including:

a. Weather.

b. Electromagnetic and radio interference.

Yes

No

c. Protection of load cell cables.

d. Sealod moisture proof junction hoxes.

Yes No

Yes No

Yes No

Yes No 
$\mathrm{S} .1 .8$

$\mathrm{S} .1 .4 .2$

S.1.8.

3011.4 .2 .

G-S . 2

3001.2

G-S.3

UR. 2.4

3001.3
4. Ad justable components:

a. Held securely in place mechanical.

Yes No

b. Calibrating controls or access to such controls supplied with provisions for sealing. Electronic controls only.

Yes No

5. Does the equipment prevent fraudulent operation or inaccurate weight values.

Yes No

6. Do the materials, design, and construction make it probable that:

a. Accuracy will be maintained.

Yes No

b. Operating components will function as intended.

Yes No

c. Adjustments will remain permanent.

Yes No

Remarks: (Include specifics for any area of non-compliance in installation and design section.)

PERFORMANCE - STATIC

CODE REFERENCE

COMPLIANCE
N.1.1

3012.1 .1
A. Must be to capacity.

B. Should utilize certified weight in its entirety.

C. May use weight substitution procedures if necessary.

D. Will utilize "error weights" for error determination.

Note: When "error" weights are utilized, the digital Lolerance does not apply.

1. Does the scale meet required tolerance. 


\section{Decreasing Load Test}

N.1.2

3012.1 .2

1. Does the scale meet required tolerance.

Yes No

Does the scale meet absolute value of acceptance tolerance.

\section{Zero Repeatability}

N.1.2.1

1. Does scale repeat zero within the minimum

Yes No tolerance.

\section{Repeatability of Indications}

G-S.5.4 3001.5 .4
1. Does the scale repeat weight indications within absolute value of acceptance tolerance.
Yes No 
In addition to the applicable separable component tests, (i.e., indicator, hopper scale, etc.), bulk weighing systems and controllers shall have dynanic tests applied as part of their type approval or pattern approval examination.

The scales utilized in the bulk weighing system must be calibrated as close as possible to zero error by a calibrating service.

Select the closest appropriate scale (vehicle, railway, or industrial), for checkweighing of the bulk material. Repeatability must be within one-fourth of tolerance.

\section{Requirements for Checkweighing Scale.}

1. Preferably mechanical with a bearn and good sensitivity.

2. Repeatable - both zero and test weight indicators.

3. Electronic scales may be used, but error weights should be utilized to determine true weight indications.

\section{Procedure for Checkweigh Scale Test.}

1. Perform section test and note errors.

2. Perform a distributed load test throughout the weight range to be utilized during the checkweighing operation and note errors.

3. Use the errors found in items 1 and 2 above to construct a correction chart to be utilized in the checkweighing operation.

Example: Vehicle scale $60^{\prime} \times 10^{\prime}$ (4 sections): 120,000 1b. capacity.

a. Section errors at 45,000 lbs.

$$
\begin{aligned}
& \text { 1. } \quad+40 \\
& 2 . \quad+40 \\
& 3 . \quad+40 \\
& 4 . \quad+50
\end{aligned}
$$

b. Distributed load errors with 29,000 lbs.:

on sections 1 and $2=+20$

on sections 3 and $4=+25$ 
c. Distributed load errors with 45,000 lbs.:

on sections 1 and $2=+40$

on sections 3 and $4=+45$

d. Distributed load errors with 75,000 lbs.:

on sections 1,2 and $3=+70$

on sections 2,3 and $4=+75$

The error graph obtained from the above exanple data is given on the next page. The two errors which will be used in the example below are obtained from the error graphs:

Weight

Tare weight of vehicle Gross weight of vehicle
23,000

67,500

\section{Error}

+21 from graph

+62 from graph

4. Formula for error compensation during checkweighing indication - (error value) = true weight.

\section{Example:}

Truck tare weight indication $=23,000$ lbs.

$23,000-(+21)=22,979$

Truck gross weight indication $=67,500 \mathrm{lbs}$.

$67,500-(+62)=67,438$

True net weight $=67,430-22,985=44,445$

$67,438-22,979=44,459$

Notes: 1. It is recominended that the checkweigh scale be adjusted and calibrated by a scale service company to bring all errors as close as practical to zero. This may eliminate the need for an error graph.

2. Scales exhibiting large differences in section errors (even though within tolerance), or a very non-linear error, should not be used for checkweighing.

3. Weight trucks intended to be used as a weight standard for error determination or checkweigh scales should have their weight verified with certified weights via a substitution comparison prior to the checkweigh scale test. 


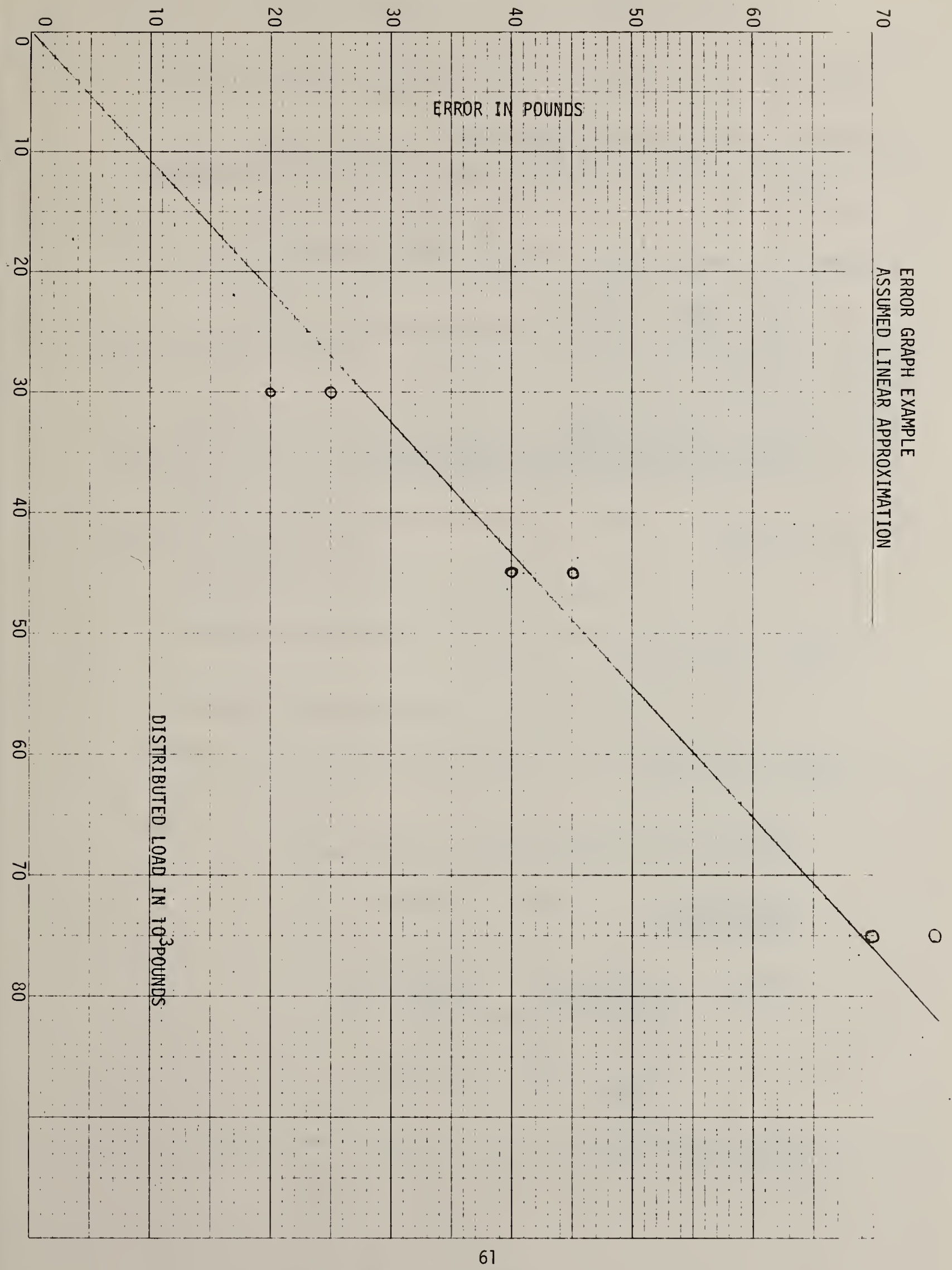


Bulk Weighing Systems and Hopper Scales.

1. Determine tare weight from checkweigh scale for the receiving vessel.

2. Load system under test with first draft of material.

a. Record weight indication.

b. Print weight if system is equipped with a printer.

3. Discharge material into receiving vessel.

a. Check return to zero.

b. If the indicator does not return to zero, record

the indicated value with appropriate sign.

4. Return receiving vessel to checkweigh scale and determine gross weight.

a. Compute the net weight based on the checkweigh scale.

5. Compare the checkweigh net weight to the system under test weight indication.

a. The checkweigh net weight is considered the standard.

6. Compute the percent error between the indicated net and the st andard net weight.

a. Formula for percent error:

Indicated net - Checkweigh Net = Difference

$\frac{\text { Difference }}{\text { Checkweigh Net }} \times 100=\%$ error

Example: Clieckweigh Net $=20,000 \mathrm{lbs}$.

Indicated Net $=20,0501 \mathrm{bs}$.

$20,050-20,000=+50$

$$
\frac{+50}{20,000} \times 100=+.25 \% \text { error }
$$

7. The maximum permissible error $i s \pm 0.30 \%$, number based on tests conducted in lalifornia. 
8. For bulk weighing systems utilizing multidrafts and a printer:

a. If the individual draft weights are printed, the scale condition before and after each draft must be printed unless the system is inhibited from operation with indications other than zero.

b. If the value printed is a net weight for one or more drafts it must be a true net weight computation.

9. Number of tests to be perforned.

a. A minimum of 15 drafts or system cycles should be checkweighed on each inspection.

10. When performing dynamic tests, all variables such as fuel in trucks, water in mixer tanks, etc., must be controlled or compensated for.

11. It is important that the receiving vessel (truck, railcar, etc.), be positioned at the same place on checkweigh scale for both tare and gross weights. Checkweigh scales should be rechecked after completion of tests.

12. Sample test data sheet.

(To be attached) 


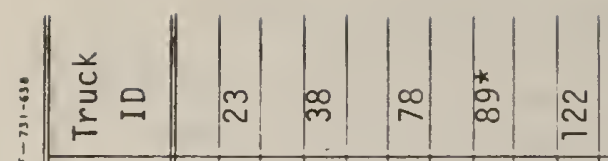

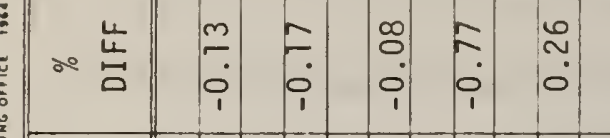

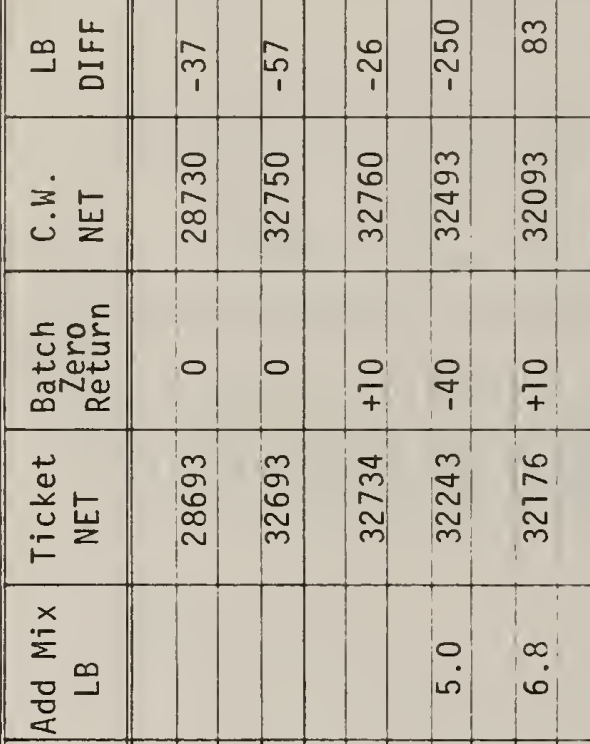

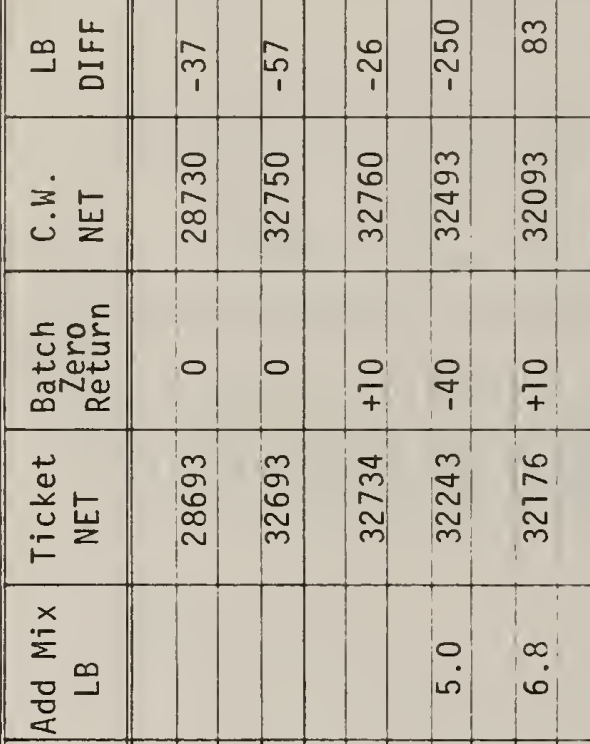

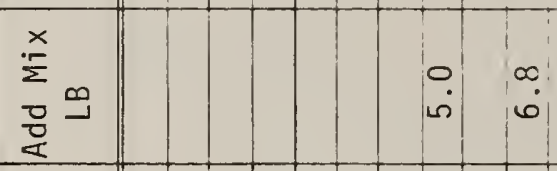

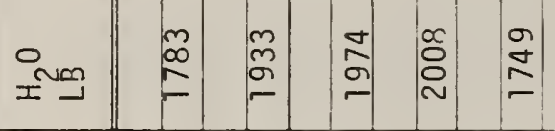

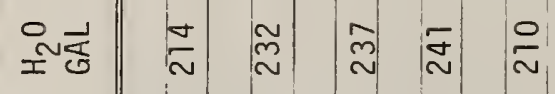

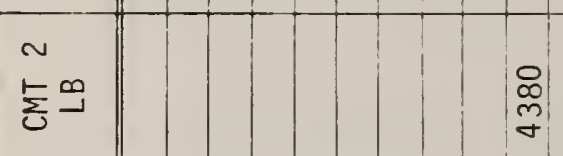

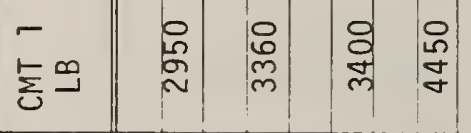

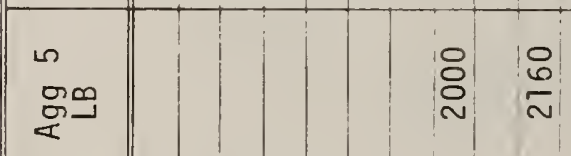

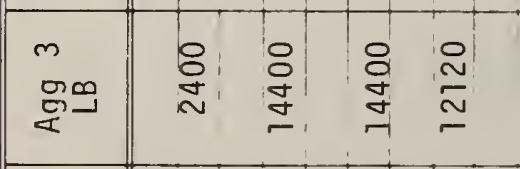

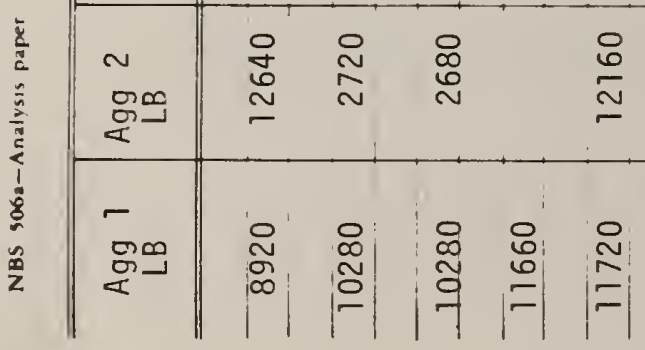

$\frac{2}{3}$

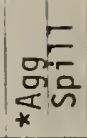

要

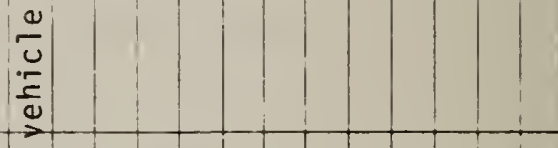

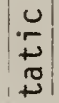

密

ร

:

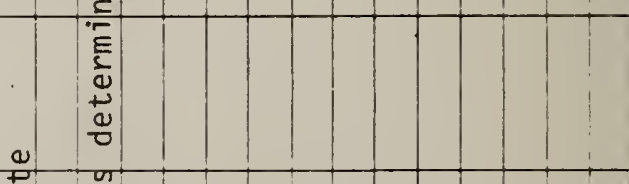

苟

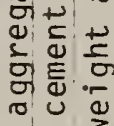

440

.
जि

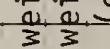

" $"$ "

嵁完: 
Automatic printers are being utilized to record the weight indications in batching plants. The printers receive signals from a measuring device, which in the past was used only for proportioning the mixture. Proportioning does not require such fine weighing accuracy as is necessary for determining the pay quantity of the resulting product. Testing a device's accuracy in a stated condition does not necessarily indicate the accuracy when the batching operation is in progress. Inadequacies such as gates failing to open all the way can be determined by dynamic testing. 


\title{
Type Approval Criteria
}

\author{
Permanence Performance Testing \\ for Scales and Electronic Cash Registers
}

Measuring devices and components whose accuracy with respect to the applicable tolerances may change significantly with use over time, are subject to permanence testing during the type approval process. Permanence testing consists of subjecting a device to actual or simulated use over a period of time and periodically testing the device for accuracy during that time.

The permanence test may be performed in the laboratory for scales with a capacity of 500 1b or 1ess. Scales with a capacity greater than $5001 \mathrm{~b}$ and other devices requiring a permanence test will be tested at a field installation where tney receive routine use. Scales with a capacity greater than $5001 \mathrm{~b}$ cannot be tested in the laboratory because current laboratory equipment cannot handle test loads of sufficient magnitude for the permanence test. The laboratory test for scales is defined in the paper titled "Laboratory Permanence Test for Scales." The procedures for permanence testing at field installations are defined in separate papers for the various devices subject to field tests.

Examples of the types of devices and components subject to permanence testing are:

1. scales in which the weighing element is permanently attached to the indicating element, and

2. weighing elements not permanently attached to the indicating element.

Devices and components which do not significantly affect measurement accuracy will generally not be subject to permanence testing but the device or component will be subject to an initial field verification test where the device must be installed in an operating system and must perform properly and within acceptance tolerances when tested at the time of installation. Examples of these types of devices or components are:

1. digital indicating elements for scales;

2. electronic cash registers;

3. Tabel or ticket printers, and

4. data processing units which incorporate label or ticket printers.

There are three different sets of field test time and tolerance parameters under consideration. The three sets represent the minimum acceptable conditions necessary to fulfill reciprocity requirements between enforcement jurisdictions. Comments are requested from members of the Task Force on National Type Approval, weights and measures officials, and industry representatives to aid in selecting the most acceptable permanence test alternative. It is hoped that the set of parameters chosen will be applied to all scales subject to a field permanence test. 
The three sets of parameters being considered are:

1. (Current method being applied in California)

The field examination to be conducted at an operating test location will consist of an initial exam followed by two additional field tests for permanence a minimum of thirty days apart. The total duration of the test is normally a minimum of 60 days from the initial test.

The initial set of tests will establish the initial errors on a device. Al1 errors on these tests must be within the acceptance tolerance.

The results of the second and third field examinations for permanence must be within maintenance tolerance and, in addition, shall not have changed by more than the absolute value of the acceptance tolerance from the initial errors for a particular test load in a given test.

2. The field examination to be conducted at an operating test location will consist of an initial set of performance tests at the start of the field permanence tests. A second set of performance tests will be conducted 20-30 days after the initial tests. The results of all tests must be within acceptance tolerances.

3. The field examination to be conducted at an operating test location will consist of an initial set of performance tests at the start of the field permanence test and a second set of performance tests conducted 40-50 days later. The results of the initial tests must be within acceptance tolerance. The errors as determined in the first set of performance tests will serve as reference numbers to which the results of the second set of performance tests will be compared. The second set of performance tests will be conducted 40-50 days after the start of the field permanence test. The results of the second test will be compared to the results of the first test for the corresponding test and test load. The errors must not have changed by more than the absolute value of the acceptance tolerance applicable to the test.

Notice that the errors may fall into the maintenance tolerance area on the second test but it is also possible that if a device has an initial test result error on one limit of the acceptance tolerance and the error shifts to the other 1 imit of acceptance tolerance, the device fails the test. 
A laboratory permanence test consists of repeatedly applying to the scale a load of between one-quarter and one-half, inclusive, of scale capacity and periodically testing the scale for accuracy during that time. Normally, a scale which is subject to the laboratory permanence test will not be subject to any field tests for the purpose of receiving type approval. A field test may be conducted if the results of the laboratory tests raise questions about the permanence of the device. Under these conditions the reasons for conducting a field permanence test will be reported to the manufacturer.

The laboratory permanence test may be performed on scales with a capacity of $5001 \mathrm{~b}$ or less. The limitation on scale capacity exists because current laboratory equipment cannot handle the loads required to test larger scales.

The accuracy of the scales under test will be determined by conducting increasing and decreasing load tests and shift tests. The scales shall be tested to capacity using known test weights. The scale should be tested to capacity at a minimum of eight equally spaced points. The minimum decreasing load test will consist of testing the scale at half-sapacity after the scale has been loaded to capacity.

Because of the ease of testing price computing scales, it is recommended that the increasing load test for computing scales (approximately $30 \mathrm{lb}$ capacity) consist of testing the scales at loads of $0.05,0.15,0.45$, and $0.95 \mathrm{lb}$ and at one pound intervals to one-half capacity and at two-pound intervals above one-half capacity to capacity. Larger capacity price computing scales should be tested in one-pound intervals to five pounds and in convenient steps to capacity so a minimum of eight additional points are tested. These are minimum tests.

The shift tests should be conducted with a load equal to one-half the scale capacity centered in the quadrants of the scale as designated below (source is NBS Handbook 112):

Bench or Counter Scales

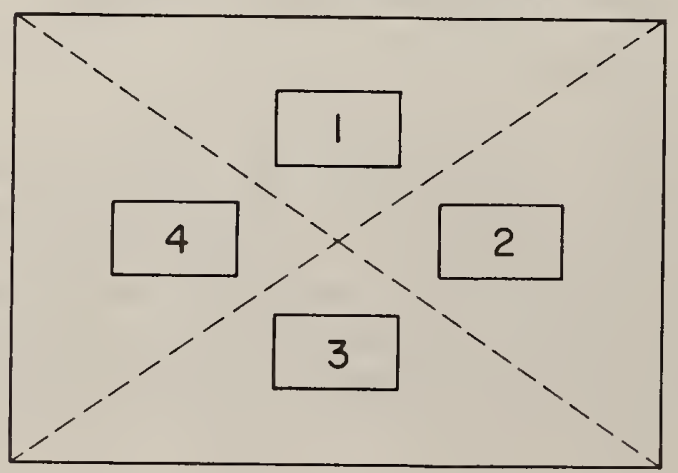

\section{Equal Arm Scales}
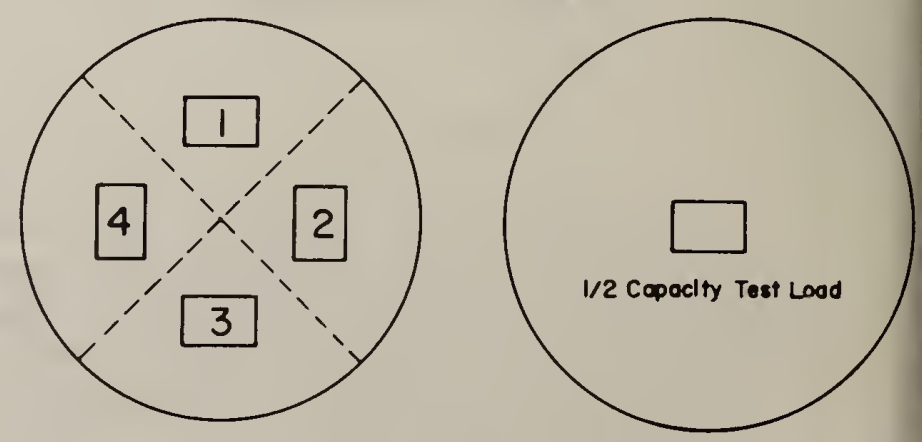

Test Each Pan Independently 
Other Small Platform Scales

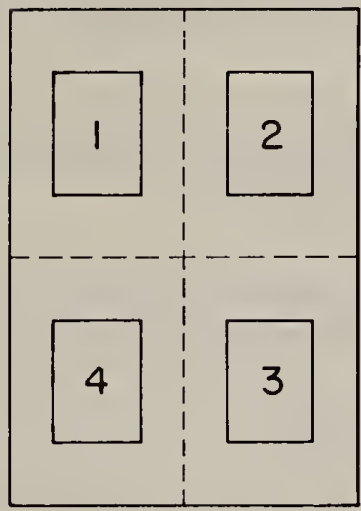

The laboratory permanence test will consist of the following:

1. Conduct a minimum of two increasing and decreasing load tests and two shift tests as the start of the permanence test.

2. Repeatedly apply a load to the scale for a minimum of 100000 weight applications. Periodically during this time a minimum of six increasing and decreasing load tests and six shift tests should be conducted. If the scale errors vary significantly with respect to the tolerance, more tests should be performed during the time the load is being applied to the scale.

The load to be repeatedly applied to the scale should be approximately onehalf scale capacity for scales with a capacity of $1001 \mathrm{~b}$ or less. For scales with a capacity greater than $100 \mathrm{lb}$ and less than or equal to $500 \mathrm{lb}$, the applied load should be between one-quarter and one-half, inclusive, of scale capacity.

3. In addition to the tests above, one set of increasing and decreasing load and shift tests should be conducted with a power supply of $100 \mathrm{~V}$ and one of $130 \mathrm{~V}$. If the scale cannot perform over this range, the scale should be tested at the minimum and maximum operating voltages provided the power supply does not exceed the limits of $100 \mathrm{~V}$ and $130 \mathrm{~V}$.

If a scale fails the permanence test, the entire test will have to be repeated. 


\author{
Type Approval Criteria \\ Performance Tests for a Vehicle Scale \\ and Axle Load* Weighing Element
}

Performance tests are tests conducted to determine compliance with the tolerance and, in the case of nonautomatic indicating scales, sensitivity requirements specified in NBS Handbook 44.

The purpose of the tests is to evaluate the scale design with respect to device accuracy and repeatability. The performance of a scale should be relatively installation independent; that is, minor modifications to the general installation design which can normally be expected in various applications should not change the scale performance by an amount that is large in relation to the applicable tolerances. Adjustments to major scale components should have predictable results.

A minimum of $30000 \mathrm{lb}$ (preferably $40000 \mathrm{lb}$ ) of known test weights is needed to test a scâle with a capacity of $1200001 \mathrm{~b}$ or less. A minimum of $400001 \mathrm{~b}$ of test weights is needed for a scale with a capacity greater than $1200001 \mathrm{~b}$ through 200000 lb capacity. More test weights should be used if available. Section tests may be conducted to the rated capacity of the sections using the available test weights. All test results should be within acceptance tolerances. Under these conditions the results from the section tests will automatically agree with the absolute value of the maintenance tolerances.

Error weight should be used whenever possible to determine the scale error for beam or digital scales. Ideally, the error should be determined to $0.1 d$ values when possible, especially if only the minimum amount of test weight is available.

It is not necessary to use error weights with dial scales. The errors for dial scales may be estimated by interpolating between graduations.

\title{
Initial Type Approval (Field) Performance Tests
}

\section{Sensitivity tests - Beam scales}

Determine the travel of the beam. Beam travel must meet Handbook 44 Scale Code S.5.1.2. Weighbeam Travel.

The sensitivity test is to be conducted at zero load before each section test and at the maximum test load for each section. The sensitivity test is to be conducted from the center of the trig loop to the top and the center of the trig loop to the bottom of the trig loop. The actual weight required to move the beam in each direction to the limiting stops should be recorded. The results up and down are expected to be approximately equal for any given test load.

* See the NBS Handbook 44 Scale Code definitions for the distinction between axle load scales and wheel load weighers. 
Sensitivity tests are to be conducted at the initial load of a strain test and at the maximum load applied to the scale. The maximum load applied to a scale to permit the testing of sensitivity near the scale capacity does not have to be known weights.

The ratio between the sensitivity of the scale at capacity versus the sensitivity at zero load should not exceed 1.5:1.

2. Section Tests - Example for a four section scale

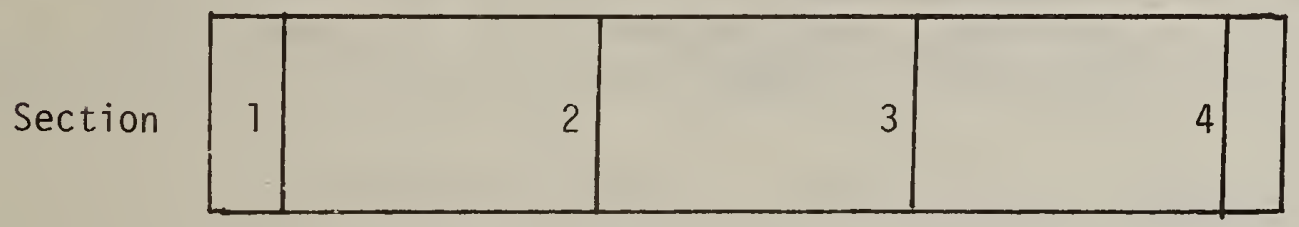

Test each section of the scale using known test weights. Do not exceed the section capacity. The load is to be distributed across the section. The load is to be removed after each section is tested to recheck the zero balance condition. If two weight carts are used, they should travel along the paths the wheels of a vehicle would take when moving across the scale. Decreasing load tests are to be avoided when testing a section. This means a truck cannot be backed on the scale to lower weights on the inner sections. Decreasing load tests should be conducted after the sections have been tested to their maximum load and the weights are being removed from the scale.

If a scale has 18 feet or more between sections, section tests should be conducted at the midpoint between sections as well.

If the scale is of a modular design, the section test should first be conducted by placing the load so it straddles the connection between the modules. Later at least one section test is to be conducted on the scale where the test load is first placed on one side of the connection line of the module and then on the side of the connection line. The test load is to be removed between these tests. The scale error should be determined at a minimum of five equally spaced test loads. Scale errors may be determined at more points if desired.

The results of the tests must be within acceptance tolerances.

3. Position tests

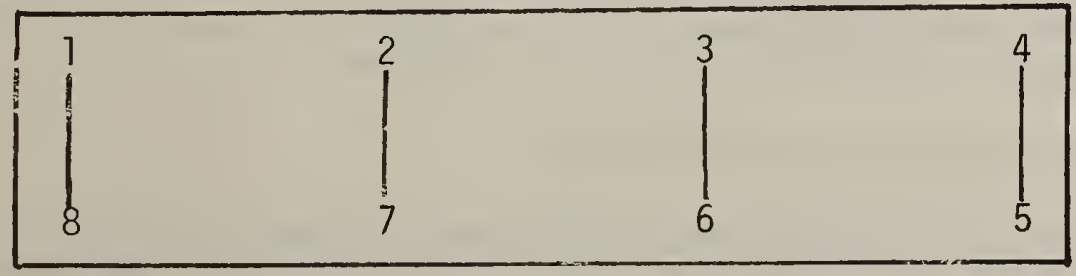


Position test are to be conducted with the test weights concentrated over each load bearing point of the scale. The load should be removed after each position test if the scale errors are near the tolerance limit or the results are questionable or if a significant zero balance change has occurred. For scales with a capacity of not more than $120000 \mathrm{lb}$, loads of at least 10000 and $20000 \mathrm{lb}$ are to be used. For scales with a capacity of more than $120000 \mathrm{lb}$ through $200000 \mathrm{lb}$, loads of at least 15000 and 30000 or 20000 and $40000 \mathrm{lb}$ are to be used for the position tests.

Normally it is expected that the errors for corresponding position tests will sum to the error for the combined load for the section test. For example, if a load of $150001 \mathrm{~b}$ on position 1 and 8 had errors of $-101 \mathrm{~b}$ and $+10 \mathrm{1b}$ respectively, it is expected that the section error at $300001 \mathrm{~b}$ should be near zero.

The results of the tests must be within acceptance tolerances.

4. The section tests as described in step 2 are to be repeated to determine scale repeatability.

5. Strain load test

Load the scale with vehicles so the addition of test weights will provide a gross load near the scale capacity. Determine the "zero reference point" for the start of the strain load test. Add the test weights to one of the end sections of the scale taking care not to overload the section.

Repeat the strain load test on the other end of the scale.

The results of the tests are expected to be within acceptance tolerances which are applied to the known test load used in the strain load test.

\section{Subsequent Type Approval (Field) Permanence Tests}

The subsequent field permanence tests shall consist of complete set of section tests as described in step 2 but excluding any tests at the midpoints between sections. Additionally, one strain load test should be conducted on each end of the scale as specified in step 5 .

The time between the initial field permanence test and the subsequent field test(s) and the tolerances to be applied will be determined by one of the three alternatives listed in the paper titled, "Permanence Performance Testing for Scales and Electronic Cash Registers". Until a decision is made by the Task Force on Type Approval, the set of parameters will be:

(Current method being applied in California)

The field examination to be conducted at an operating test location will consist of an initial exam followed by two additional field tests for permanence a minimum of thirty days apart. The total duration of the test is normally a minimum of 60 days from the initial test. 
The initial set of tests will establish the initial errors on a device. All errors on these tests must be within the acceptance tolerance.

The results of the second and third field examinations for permanence must be within maintenance tolerance and, in addition, shall not have changed by more than the absolute value of the acceptance tolerance from the initial errors for a particular test load in a given test.

If a device fails any of the subsequent permanence tests, the entire permanence test must be repeated. The criteria for repeated permanence tests will be the method currently being used by California as stated above. It is anticipated that these criteria will be used for any repeat field permanence test regardless of the ultimate choice of alternative permanence tests selected by the Task Force on National Type Approval.

\section{Caution Regarding Load Concentration}

A warning was received that jurisdictions concentrating large loads on scale platforms by using weight carts or test equipment using hydraulic jacks may be in danger of exceeding the maximum pound per square inch load specification for the deck. This conditon may arise because the small tire area of the weight cart in contact with the deck surface could result in a very large load concentration over an unusually small area. This could cause local damage to the scale deck.

This situation may occur with weight carts having very narrow or short wheel bases and small solid rubber tires. This is particularly likely to cause a problem on steel plate decks and could also result in damage to manhole covers. If the load capacities of weight carts are increased beyond $250001 \mathrm{~b}$ while maintaining solid tread wheels, then it is possible that some concrete decks could be damaged. 


\section{DRAFT}

\section{Type Approval Criteria}

Performance Tests for Platform Scales Except

Vehicle, Railroad, Livestock, and Digital Counter (Bench) Scale

Performance tests are tests conducted to determine compliance with the tolerance and, in the case of nonautomatic indicating scales, sensitivity requirements specified in NBS Handbook 44. The purpose of the tests is to evaluate the scale design with respect to device accuracy and repeatability. The performance of a scale should be relatively installation independent; that is, minor modifications to the general installation design which can normally be expected in various applications should not change the scale performance by an amount that is large in relation to the applicable tolerances. Adjustments to major scale components should have predictable results.

Scales with a capacity of $200001 \mathrm{~b}$ or less should be tested to capacity using known test weights. A minimum of $20000 \mathrm{lb}$ of test weights should be used on larger scales. Ideally, all scales should be tested to capacity using known test weights. All test results are expected to be within acceptance tolerances.

Error weights should be used whenever possible to determine the scale error for beam scales. The guideline titled the "Use of Error Weights on Digital Scales" may be followed to determine when error weights should be used with digital scales. It is not necessary to use error weights with dial scales. The errors for dial scales may be estimated by interpolating between graduations.

\section{Initial Type Approval Performance Tests}

\section{Sensitivity tests - Beam scales}

Determine the travel of the beam. The beam travel must comply with NBS Handbook 44 Scale Code S.5.2. Weighbeam Travel.

The sensitivity test is to be conducted at zero load and at capacity load. The sensitivity test is to be conducted from the center of the trig loop to the top and the center of the trig loop to the bottom. The weight required to move the beam in each direction to the limiting stops should be recorded. The results up and down are expected to be approximately equal for any given test load.

The ratio between the sensitivity of the scale at capacity versus the sensitivity at zero load should not exceed $1.5: 1$.

\section{Increasing load tests -}

Three increasing and decreasing load tests should be conducted to determine device repeatability. A minimum of five different test loads should be applied; more are preferred. Whenever practical, each notch on a counter (bench) scale beam should be tested at least once. The results for a given test load under similar conditions should repeat within the absolute value of the acceptance tolerance. The term "under similar conditions" refers to the load position on the increasing and decreasing load tests. With respect to repeatability, the test results from the increasing load test should be reviewed separately from 
the decreasing load test results. However, the results from both tests are required to be within acceptance tolerances. Similarly, repeatability for each position in the shift test should be considered separately from the other shift test positions.

\section{Shift tests -}

Shift tests are conducted to determine the scale's ability to accurately weigh off-center loads. The test may also provide information on the structural design and strength of the weighbridge, the quality control process used to adjust the corners of the scale and possibly on the sensitivity of the device accuracy to installation conditions. Bench scales should be tested at one-half capacity with the load positioned as described in Handbook 112. Larger scales may be tested by either the corner test method using test weights equal to one-fourth capacity or the quadrant test (weights centered in each quadrant of the scale) using weights equal to one-half capacity. The diagrams in Handbook 112 specify the proper positions.

A minimum of three shift tests should be conducted. Ideally two of the shift tests should be quadrant tests and one should be a corner test. Either test may reveal a problem that may not appear if only one type of shift test is. conducted.

The results of all increasing load and shift tests conducted during the initial performance tests must be within acceptance tolerances.

\section{Subsequent Type Approval Permanence Tests}

The permanence test for counter and low capacity platform scales which have a capacity of $500 \mathrm{lb}$ or less may be conducted in the laboratory. The procedures for these tests are described in the paper titled, "Laboratory Permanence Test for Scales". A field test may be conducted if the results of the laboratory test.s raised questions about the permanence of the device. Under these conditions, the reasons for conducting a field permanence test will be reported to the manufacturer.

Scales which cannot be tested in the laboratory are subject to field permanence tests. The initial type approval performance tests will normally be conducted at the field site and will start the permanence test phase.

On subsequent permanence test examinations a minimum of one increasing and decreasing load test and one quadrant shift test should be conducted. If the test results are marginally within tolerance or out of tolerance, at least one more series of tests should be conducted to verify the results and determine device repeatability.

The time between the initial field permanence test and the subsequent field test(s) and the tolerances to be applied will be determined by one of the three alternatives 1 isted in the paper titled, "Permanence Performance Testing for Scales and Electronic Cash Registers". Until a decision is made by the Task Force on Type Approval, the set of parameters will be: 
(Current method being applied in California)

The field examination to be conducted at an operating test location will consist of an initial exam followed by two additional field tests for permanence a minimum of thirty days apart. The total duration of the test is normally a minimum of 60 days from the initial test.

The initial set of tests will establish the initial errors on a device. All errors on these tests must be within the acceptance tolerance.

The results of the second and third field examinations for permanence must be within maintenance tolerance and, in addition, shall not have changed by more than the absolute value of the acceptance tolerance from the initial errors for a particular test load in a given test.

If a device fails any of the subsequent permanence tests, the entire permanence test must be repeated. The criteria for repeated permanence tests will be the method currently being used by California as stated above. It is anticipated that thesecriteria will be used for any repeat field permanence test regardless of the ultimate choice of alternative permanence tests selected by the Task Force on National Type Approval. 


\section{DRAFT \\ Type Approval Criteria \\ Performance Tests for Digital Counter (Bench) \\ and Price Computing Scales}

Performance tests are tests conducted to determine compliance with the tolerance and, in the case of nonautomatic indicating scales, sensitivity requirements specified in NBS Handbook 44. The purpose of the tests is to evaluate the scale design with respect to device accuracy and repeatability.

Because these scales are normally portable, they are usually supplied with level bubbles to aid in keeping the scale in a level position. If a portable scale is not equipped with a level-indicating mechanism, the scale must be tested in an out-of-level condition in addition to the normal performance tests, to determine compliance with Scale Code paragraph S.2.3. Leveling-Indicating Means.

The guideline for the "Use of Error Weights on Digital Scales" may be followed to decide if it is necessary to use error weights to determine scale errors.

Since digital counter (bench) and price computing scales normally have capacities of $5001 \mathrm{lb}$ or $1 \mathrm{ess}$, the permanence test for these scales may be conducted in the laboratory. The procedures for these tests are described in the paper titled, "Laboratory Permanence Test for Scales". A field test may be conducted if the results of the laboratory tests raised questions about the permanence of the device. Under these conditions, the reasons for conducting a field permanence test will be reported to the manufacturer.

The laboratory permanence test is strongly recommended for small scales because it requires less time, is more efficient, is more convenient for the testing official, and many times is less expensive to the manufacturer. In the event that a field permanence test must be conducted, procedures are provided below.

\section{Initial Type Approval (Field) Performance Tests}

A minimum of two increasing and decreasing load tests and two shift tests are to be conducted at the start of the field permanence test. The scales are to be tested to capacity using known test weights. The test results are expected to be within acceptance tolerance.

Out-of-Level Tests

If a portable scale is not equipped with a level bubble or other level indicating mechanism, a series of out-of-level tests must be conducted. A scale is considered portable if its dimensions of 1 ength and width are 24 inches by 18 inches or less, respectively, and the device weighs 35 pounds or 1 ess. Regardless of dimensions, any scale with hand grips or on wheels is considered portable.

First place the scale three degrees or five percent out of level with respect to the length axis of the scale. The scale should then be rezeroed. Conduct increasing and decreasing load tests and a shift test. The results must not have changed by more than the applicable acceptance tolerance from the error obtained when the scale was in a level position. 
It is suggested that the shift test be conducted first since this test frequently reveals an accuracy problem.

Next, place the scale three degrees or five percent out of level with respect to the width axis of the scale. The scale should again be rezeroed. Conduct the increasing and decreasing load and shift tests. The tolerance application is as stated above.

If the scale fails any of these tests, a level-indicating mechanism is needed.

Subsequent Type Approval (Field) Permanence Tests

One set of increasing and decreasing load tests and one shift test should be conducted. The scales are to be tested to capacity using known test weights. If the test results are marginally within tolerance or out of tolerance, at least one more series of tests should be conducted to verify the results and determine device repeatability.

The time between the initial field permanence test and the subsequent field test(s) and the tolerances to be applied will be determined by one of the three alternatives listed in the paper titled, "Permanence Performance Testing for Scales and Electronic Cash Registers". Until a decision is made by the Task Force on Type Approval, the set of parameters will be:

(Current method being applied in California)

The field examination to be conducted at an operating test location will consist of an initial exam followed by two additional field tests for permanence a minimum of thirty days apart. The total duration of the test is normally a minimum of 60 days from the initial test.

The initial set of tests will establish the initial errors on a device. All errors on these tests must be within the acceptance tolerance.

The results of the second and third field examinations for permanence must be within maintenance tolerance and, in addition, shall not have changed by more than the absolute value of the acceptance tolerance from the initial errors for a particular test load in a given test.

If a device fails any of the subsequent permanence tests, the entire permanence test must be repeated. The criteria for repeated permanence tests will be the method currently being used by California as stated above. It is anticipated that thesecriteria will be used for any repeat field permanence test regardless of the ultimate choice of alternative permanence tests selected by the Task Force on National Type Approval. 


\section{Type Approval Criteria Guideline \\ Use of Error Weights on Digital Scales}

The purpose of determining the scale errors in the increasing and decreasing load tests in a type approval examination is to determine the accuracy performance curve of the scale. The shift test is conducted to determine the scale's ability to weigh off-center loads. In both cases, the scale errors must be checked for compliance to established tolerances. The most accurate method of determining these errors is by the use of error weights.

Error weights may be used to test any scale subject to a type approval examination. When error weights are used, the one-half scale division for digital indications (Handbook 44 Scale Code T.1.3.) will not be applied. The scale must perform within acceptance tolerances.

The determination of errors in a digital scale by the use of error weights is a slow process. When the tolerance applied to a scale at a capacity load consists of several scale divisions, the accuracy performance curve can be determined quite reliably by reading the scale error directly from the displayed weight values. Whenever the scale error is determined by direct reading, the tolerance that would normally be applied should be increased by one-half of a scale division as stated in NBS Handbook 44 Scale Code T.1.3. . This is necessary because the actual weight value may be plus or minus one-half of a scale division from the displayed weight value. This additional tolerance is provided so the scale is not penalized by the direct reading of the scale errors. If the scale error as determined by direct reading exceeds the direct. reading tolerance, the scale is out of tolerance.

To aid weights and measures officials to determine when to use error weights to determine scale errors and when to direct read scale errors, the following guidelines are suggested for type approval examinations:

(a) If a scale has 5000 scale divisions or more and the scale is tested to capacity using known test weights, then the direct reading of scale errors is satisfactory. In this case if the scale tolerance is $0.05 \%$, then the direct reading tolerance at capacity is three divisions.

(b) Scale errors are to be determined by using error weights when the total amount of test weights represents less than 5000 scale divisions.

(c) Computing scales may be tested by the direct reading of errors because the scales are generally well within tolerance and many tests can be run easily in a short period of time to collect many data points for the accuracy performance curve. If the test results are marginal with respect to the tolerance the error weights should be used. 
(d) Scale errors can be determined in type approval tests by direct reading if the display resolution can be increased by a factor of ten times the actual resolution being requested for type approval. This is particularly applicable to scales which would normally have less than 5000 scale divisions in the weight range covered by the application of known test weights. The increased resolution would give readings equivalent to that obtained by using error weights equal to 0.1 scale division. The width of zero, zero tracking, and zone of uncertainly tests must be conducted with the scale resolution set for the maximum number of divisions being requested for type approval. 
This test method is applicable to any digital scale. The explanation will be given for a $120000 \times 201 \mathrm{~b}$ vehicle scale. The letter "d" will mean scale division. A scale division is defined as the difference between two consecutive numbers on a digital scale. For the vehicle scale above, the scale division will be $20 \mathrm{lb}$. Each displayed weight value will have a range of weight over which the scale will display a specific weight value. For example, the vehicle scale above will theoretically display the weight value $500001 \mathrm{~b}$ over a weight range of $49990 \mathrm{lb}$ to $50010 \mathrm{lb}$ because a digital device is required to round off weight values.

This means a scale division has a certain "width" or range over which it indicates that particular weight value. When a weight value is used with the word "division", it will identify the particular scale division being discussed. In the example above this was the $500001 \mathrm{~b}$ division.

To test a scale using error weights, it is necessary to know "where you are" within a scale division; i.e., to have a reference point. The "zero reference point" will be the point within the zero division at which the scale is located when it is under zero load. This is explained in more detail later. The most useful values for the zero reference point are the center of zero or the leading or trailing edge of the zone of uncertainty.

The smallest weight value that will be added or removed from the scale will be $0.1 d$. The use of weight values this small will stretch the limits of readability of the scale and will have an uncertainty of at least $0.1 d$ depending upon the scale, the installation, and environmental conditions. This uncertainty is recognized along with the repeatability of the scale and is considered when reviewing data taken to the $0.1 \mathrm{~d}$ even though no further comments will be made about this uncertainty in the remainder of this explanation.

The term "breakpoint" will be used to refer to the edge of the zone of uncertainty $(\mathrm{zu})$ on either end of a division. For example, if the scale does not have zero tracking, the addition of weight in $0.1 d$ steps will eventually result in the scale alternately displaying 0 or $1 d$ or a fixed 1d (20 1b in the example below). The point where the scale first starts to enter the zone of uncertainty will be called the breakpoint.

A word of caution is needed about microprocessor-based scales that make use of built-in hysteresis or "antijitter" programs. This is becoming a common feature in digital electronic scales and is used to reduce the zone of uncertainty and provide a very stable indication. Basically, built-in hysteresis means that once a scale has selected a particular weight value to be displayed, a change in weight of approximately $0.1 d$ to $0.2 \mathrm{~d}$ is required to change the weight display although the scale may 
actually be in what is normally the zone of uncertainty. This is not zero tracking because the weight may be applied in small steps and this will produce the same result as if the weight were applied in one step. This makes the zone of uncertainty or breakpoint appear to move about depending upon the direction (above or below) in which the zone of uncertainty is approached.

This discussion can be visualized by considering each digital scale division as being comprised of ten smaller divisions each having a value of $0.1 d$. The center of a division is between the two middle $0.1 d$ smaller divisions.

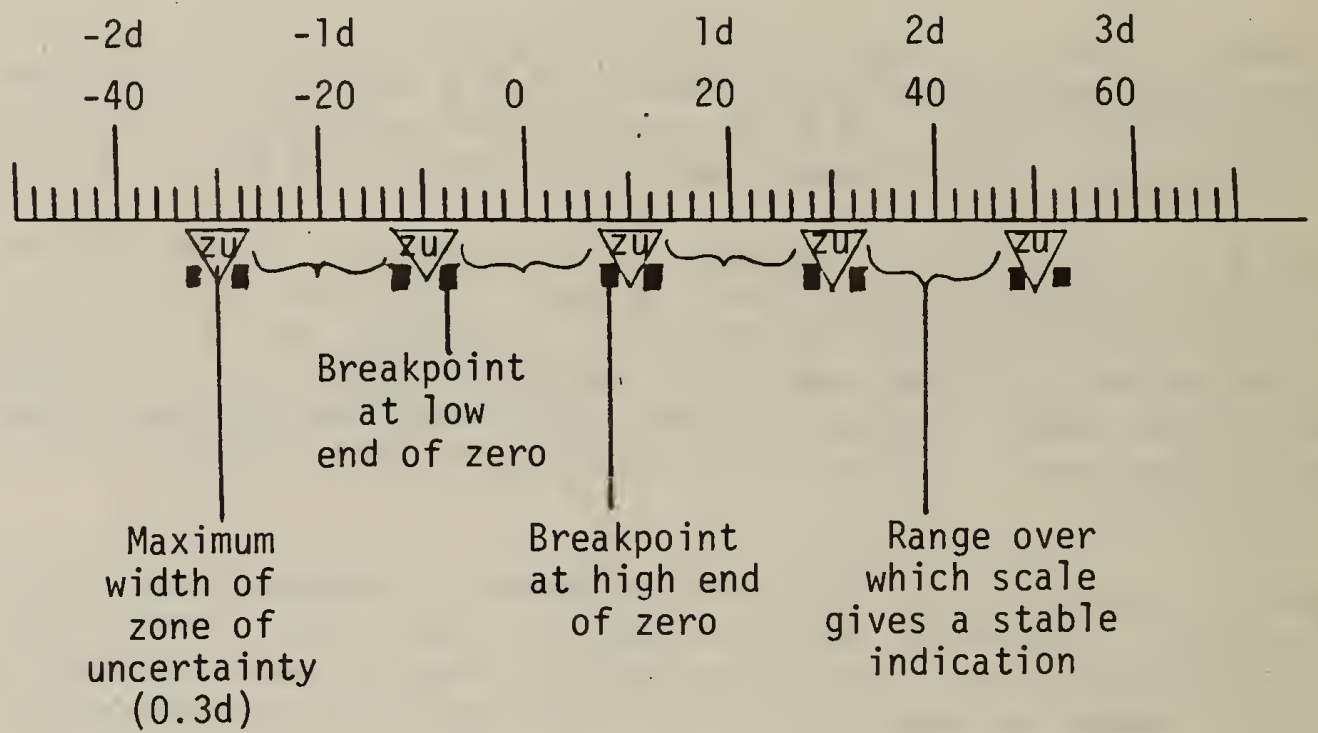

If a scale is equipped with zero tracking, we can normally assume the zero reference point is at the center of the zero division.

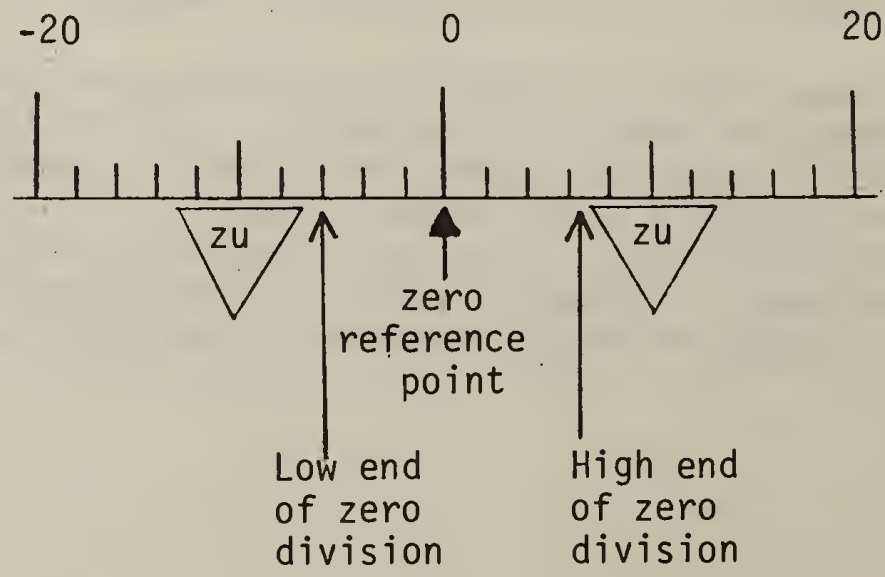


If a scale is not equipped with zero tracking, the zero reference point (the point from which the scale starts within the zero division) may be anywhere within the zero division.

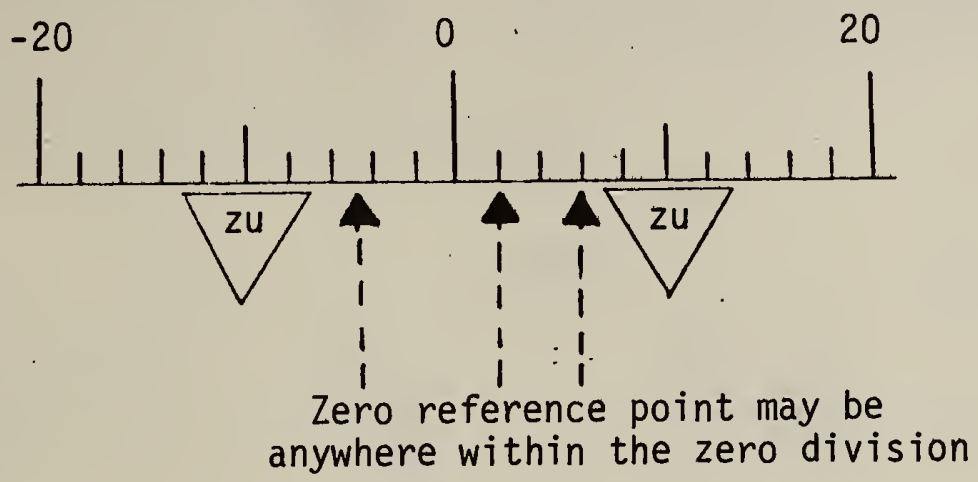

To test a digital scale by using error weights, it will be convenient to select the center of zero as the zero reference point. Initially, place error weights on the scale and adjust the zero mechanism to obta in a zero display. If the scale has zero tracking, it can be assumed that the zero reference point is at the center of zero. If the scale does not have zero tracking, it is necessary to adjust the zero mechanism or change the error weights to set the zero reference point at the center of zero.

For scales without zero tracking first determine the width of the stable zero indication. This is done by removing weight from the scale in $0.1 d$ steps. Eventually you will reach the breakpoint on the low edge of zero. Add $0.1 d$ to return you to a stable zero indication. This will put you just within the stable zero division on the low edge of zero and is your starting point to determine the width of zero.

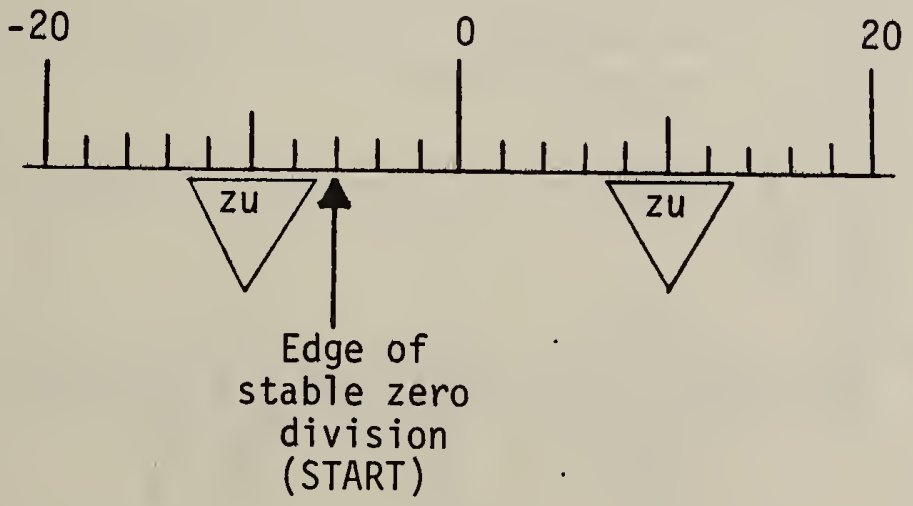


Now add weight in multiples of $0.1 d(2 \mathrm{lb})$ to get close to the breakpoint on the high end of the zero division. Continue to add weight in $0.1 d$ (2 1b) steps until you just enter the zone of uncertainty (breakpoint) on the high end of zero.

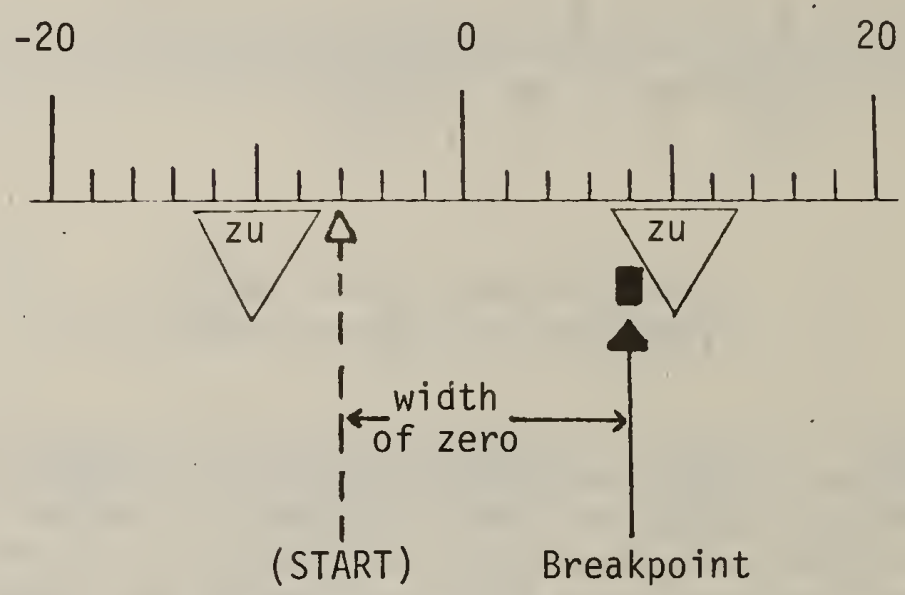

The amount of weight added from the start position is considered to be the width of the zero division. Although the final added weight step placed you at the breakpoint, this is not considered to put the scale at a disadvantage to meet the width of zero requirement because the start position was in the stable zero division and conceivably could have been almost $0.1 d$ inside the low end of the zero division when the test started.

At this time it is convenient to test the width of the zone of uncertainty because you have worked your way to the breakpoint on the high end of the zero division. Add weight in $0.1 \mathrm{~d}$ (2 lb) steps until a stable $20 \mathrm{lb}$ (1d) indication is obtained. This should not require more than $0.3 d$ ( 6 1b) since the zone of uncertainty is required to be less than or equal to $0.3 d$.

Return to the breakpoint on the high end of the zero division. Remove half the weight that represented the width of zero. This will put the zero reference point at the center of the zero divison. Equal weight will have to be added or removed to reach the breakpoints on the high and low ends of the zero division.

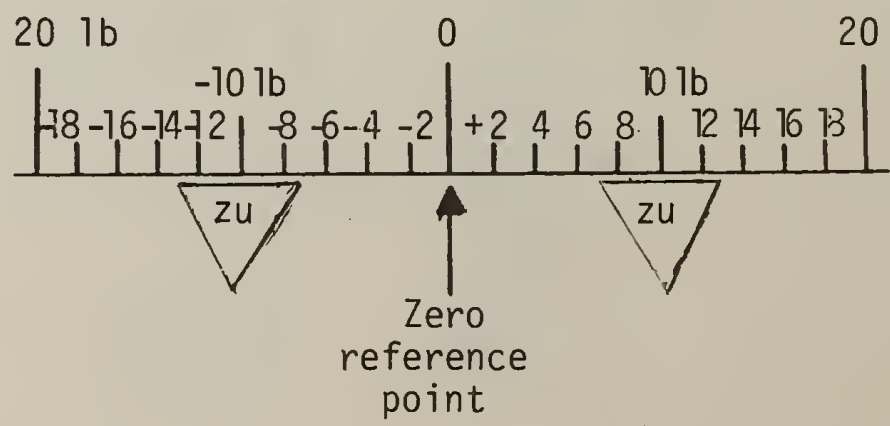


This means that the final scale position is 6 lb below the center of the division. Since the zero reference point was the center of the zero division, the error is $-61 \mathrm{~b}$.

Suppose that the test load were increased to $200001 \mathrm{~b}$ and that the scale indicated a stable 20020 lb. We would know that the scale indication represents a weight between 20012 and 20028 (16 1b range) since the zone of uncertainty is $4 \mathrm{lb}$ wide. Suppose that only $41 \mathrm{~b}$ were needed to reach the breakpoint on the high end of the $200201 \mathrm{~b}$ division. This could be represented as

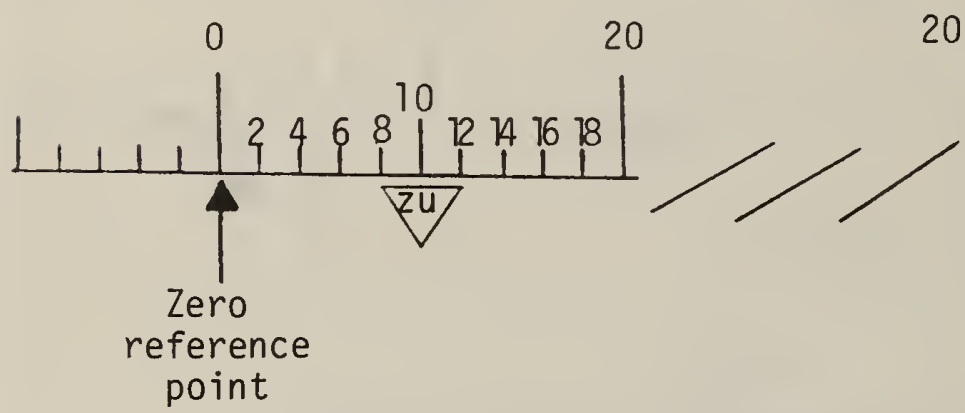

20020

20040

This scale error could be counted from the center of the $20000 \mathrm{lb}$ division to reveal an error of $24 \mathrm{lb}$. This could be computed as follows:

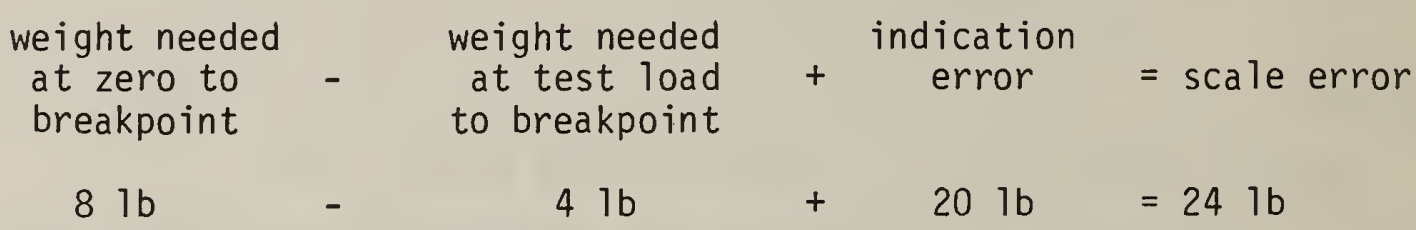

Suppose that the scale indicated $19980 \mathrm{lb}$ and that $12 \mathrm{lb}$ were needed to reach the breakpoint. The scale error would be computed as

$$
81 b-(12)+(-201 b)=-241 b
$$

This can be verified on the diagram as:

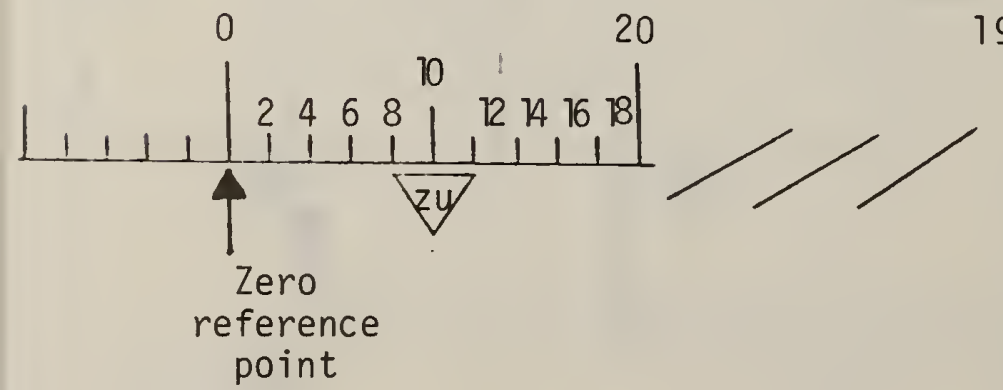

19960

19980

$20000 \quad 1 b$

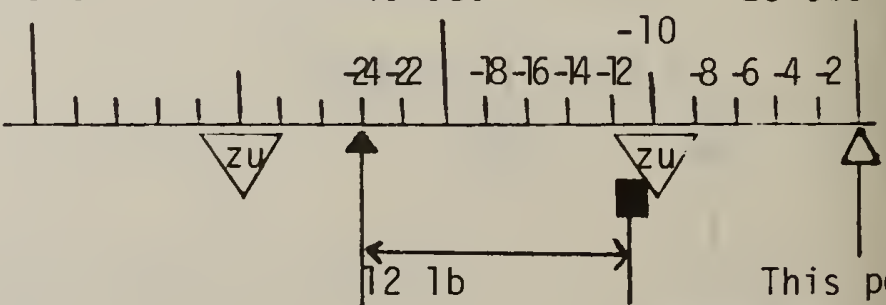
zero error 
Notice in these examples that weight was always added to reach the breakpoint on the high end of the display division. For simplicity this is the only method described. This method of calculation is valid even if the indication error is more than one division. 

NBS-114A (REV. 2-8C)

U.S. DEPT. OF COMM.

BIBLIOGRAPHIC DATA

SHEET (See instructions)

1. PUBLICATION OR REPORT NO.

NBSIR $80-2179$

2. Performing Organ. Report No.y 3. Publication Date

December 1980

4. TITLE AND SUBTITLE

Qraft Type Approval Criteria and Test Procedures

5. AUTHOR(S)

Henry V. Oppermann

6. PERFORMING ORGANIZATION (If joint or other than NBS, see instructions)

7. Contract/Grant No.

NATIONAL BUREAU OF STANDARDS

DEPARTMENT OF COMMERCE

WASHINGTON, D.C. 20234

9. SPONSORING ORGANIZATION NAME AND COMPLETE ADDRESS (Street, City, Stote, $\overline{\text { ZIP) }}$

8. Type of Report \& Period Covered

\$ame as Item 6

10. SUPPLEMENTARY NOTES

[ Document describes a computer program; SF-185, FIPS Software Summary, is attached.

11. ABSTRACT (A 200-word or less factual summary of most significant information. If document includes a significant bibliography or literature survey, mention it here)

This document is a preliminary draft of a possible handbook on type approval criteria and procedures for weighing and measuring devices. The distribution of the draft is to solicit comments on whether the information is useful to manufacturers and weights and measures officials. The responses will determine if further development of written type approval criteria in the measurement areas covered in the draft and in other measurement areas should be pursued.

The development of checklists and test procedures is an effort to make both the manufacturer and the enforcement official aware of criteria currently being used in type approval examinations. It is also an attempt to standardize the criteria and test methods. The distribution of this draft document will provide a basis for discussion of possible directions for a national type approval program in the future. The checklists and test methods are intended to be sufficiently flexible to be easily changed to keep pace with technology and to permit innovation in the design of weighing and measuring equipment.

12. KEY WORDS (Six to twelve entries; alphabetical order: capitalize only proper names; and separate key words by semicolons) digital indication; error weights; performance tests; permanence tests; scale division; tare; test weights; tolerances; type approval.

13. AVAILABILITY

[] Unlimited

XX| For Official Distribution. Do Not Release to NTIS

$\square$ Order From Superintendent of Documents, U.S. Government Printing Office, Washington, D.C. 20402.

14. NO. OF

PRINTED PAGES

94

[ Order From National Technical Information Service (NTIS), Springfield, VA. 22I6I

15. Price 
